\title{
Interaction of Cleat-Matrix on Coal Permeability from Experimental Observations and Numerical Analysis
}

\author{
Chunguang Wang $\mathbb{D}^{1,2}$ Yuxiao Zang, ${ }^{1}$ Linsen Wang, ${ }^{1}$ Zhongwei Chen $\mathbb{D}^{1,3}$ Guanglei Cui, ${ }^{4}$ \\ Kunkun Fan, ${ }^{1}$ and Weitao Liu ${ }^{1}$ \\ ${ }^{1}$ State Key Laboratory of Mining Disaster Prevention and Control Co-founded by Shandong Province and the Ministry of Science \\ and Technology, Shandong University of Science and Technology, China \\ ${ }^{2}$ State Key Laboratory of Geomechanics and Geotechnical Engineering, Institute of Rock and Soil Mechanics, Chinese Academy \\ of Sciences, Wuhan 430071, China \\ ${ }^{3}$ School of Mechanical and Mining Engineering, The University of Queensland, St. Lucia, QLD 4074, Australia \\ ${ }^{4}$ Key Laboratory of Ministry of Education on Safe Mining of Deep Metal Mines, Northeastern University, Shenyang 110004, China
}

Correspondence should be addressed to Zhongwei Chen; zhongwei.chen@uq.edu.au

Received 9 July 2019; Revised 2 October 2019; Accepted 8 October 2019; Published 18 November 2019

Academic Editor: Paolo Madonia

Copyright (c) 2019 Chunguang Wang et al. This is an open access article distributed under the Creative Commons Attribution License, which permits unrestricted use, distribution, and reproduction in any medium, provided the original work is properly cited.

\begin{abstract}
Gas transport through porous coal contains gas laminar flow in the cleat network and gas adsorption/diffusion in the matrix block. Since permeable capacity of the cleat is greater than that of the matrix, change of the matrix pressure readily lags behind change in the cleat pressure. Such unsynchronized pressure changes can result in a complex compatible deformation of a cleat-matrix system, significantly affecting the coal permeability. In this paper, we investigated the cleat-matrix interaction on coal permeability by using a modified pressure pulse decay method integrated with numerical analysis. The experimental results indicate that the bulk volume of the coal sample rapidly expanded at the beginning of gas injection, and then the volume expansion rate of the coal sample slowed down as the downstream pressure of the coal sample gradually equilibrated with the upstream pressure. During this process, the coal permeability was observed to gradually decrease with time. Numerical analysis results indicate that gas transport from the cleat to the matrix can attenuate the differential pressure between the cleat and the matrix. A smaller ratio of initial matrix permeability to initial cleat permeability can prolong decay duration of the differential pressure inside the cleat-matrix system. Although the coal sample is subjected to a stress-controlled condition, the coal permeability response to gas diffusion is closer to the case using a constant volume boundary. The dynamic change of coal permeability is significantly affected by the cleat-matrix interaction, in cases where the short-term change is mainly attributable to the cleat network and the long-term change is controlled by matrix swelling/shrinkage.
\end{abstract}

\section{Introduction}

Coal bed methane is an unconventional gas whose storage/transport in a coal reservoir is different from that in a carbonate reservoir. Given that coal permeability is predominated by cleats, it is commonly assumed that the Darcy flow is a result of flow in the cleat system and that the contribution of flow in the coal matrix to the Darcy flow can be neglected. According to considerable labora- tory measurements and field observations, coal permeability is controlled by two factors: the pore pressure change can alter effective stress and consequently increase or decrease the bulk volume of the coal [1-7]; gas adsorption/desorption can swell or shrink the coal matrix, which can compress or close the cleat aperture. Of these two factors, gas adsorption has a greater impact on coal permeability. During coal bed methane extraction, gas in the cleat network first discharges, causing a drop in the reservoir pressure, 
which in turn leads to gas transfer due to gas gradients between the matrix and the cleat. Current assumptions on the mass transfer between the matrix and the cleat can be categorized into (i) equilibrium state, (ii) nonequilibrium and pseudosteady state, and (iii) nonequilibrium and nonsteady state.

(i) The equilibrium state assumption is that gas adsorption/desorption on the matrix occurs instantaneously. Here, the matrix pressure is always equal to the cleat pressure [8-10]. Under this assumption, the effective stress of the bulk coal is usually expressed as $\sigma_{e}=\sigma-\xi p$, where $\sigma_{e}$ is the effective stress, $\sigma$ is the total stress, $\xi$ is the Biot coefficient, and $p$ is the pore pressure. In order to simplify the calculation, $\alpha$ is set to unity. This means that interconnected pores of the coal matrix is well developed. The gas-bearing coal matrix provides a mass source term for the gas flow equation [11] via gas adsorption/desorption. This assumption ignores the gas supply hysteresis effect from the matrix blocks and consequently underestimates coal permeability

(ii) The nonequilibrium and pseudosteady state assumption is that a time-dependent gas transfer is driven by pore pressure gradient between the coal matrix and the cleat [12]. The cleat pressure shares the same finite mesh element with the matrix pressure, which is relevant to the numerical modeling of coal permeability evolution. This assumption not only can investigate gas mass exchange between the matrix and the cleat but also can simulate the gas diffusion process in the coal matrix [13-15]. The advantage of this assumption is that it is applicable to dualporosity media. However, the pseudosteady state assumption is unable to interpret inhomogeneous deformation behavior of the matrix block when the size of the coal matrix becomes larger

(iii) The nonequilibrium and nonsteady state assumption is that coal matrix pressure changes dynamically and the gas flow rate is proportional to the pressure gradient. Under this assumption, both the matrix pressure and the cleat pressure can be set as an independent variable in their respective computational domain [16-21]. The geomechanic properties of the matrix block such as size and permeability also affect the tempospatial distribution of pore pressure. For instance, the pressure gradient attenuation will become faster when the matrix permeability increases. As a result, the gas transfer between the matrix and the cleat is likely to decay rapidly. In this case, deviation from the equilibrium state model (Assumption I) and the nonequilibrium model (Assumption II) may be negligible. In fact, gas permeability of the coal matrix is extremely low. Moreover, the coal matrix size is not small enough to ignore. If the equilibrium state model is used, then the gas flow in the cleat is possibly overestimated. Therefore, it is necessary to study tempospatial gas transfer and its impact on the evolution of porosity/permeability of coal

Most permeability measurements on porous media are required to be conducted when the pore pressure reaches the equilibrium state [22-30]. This requirement suggests that both the matrix pressure and the cleat pressure are held constant during testing. Micro-CT imaging shows that the pore structure of the coal matrix consists of connected pores and nonconnected pores [31, 32]. The gas pressure of the connected pore system is readily increased up to the cleat network pressure, while the gas pressure in nonconnected pores remains at the initial value. Under such conditions, the pore pressure of coal is characterized by nonlinear distribution. Gas diffusion in the matrix takes a longer time to reach the equilibrium state, which causes the matrix pressure to lag behind the cleat pressure. The unsynchronized changes in effective stress between the matrix and the cleat can alter coal permeability by the matrix deformation narrowing/widening the cleat aperture. To resolve these issues, several researchers introduced a deformation coefficient into the matchstick model to evaluate the impact of adsorption-induced deformation on the cleat aperture [33-36]. Although these models can investigate the cleat-matrix interactions induced by matrix swelling, the effective stress-controlled matrix deformation on coal permeability has received little attention. Therefore, it is challenging to create accurate reservoir simulations of this behavior. This permeability variation is also important for enhanced coal bed methane such as $\mathrm{N}_{2}$ and $\mathrm{CO}_{2}$ that are injected to improve recovery of reservoir gases.

In our previous studies $[37,38]$, gas permeability evolution resulting from competition between gas adsorption effect and mechanical compression has been investigated by using numerical modeling. We also observed the deformation evolution of porous structure of coal sample during gas injection process [39]. It is experimentally found that gas convection between the matrix and the cleat can dynamically control bulk deformation of coal. These findings reveal the gas permeability change induced by gas unsteady flow process. Conventional laboratory permeability measurements only provide relation of permeability and gas pressure/effective stress, which can estimate cleat compressibility under steady-state flow condition.

Therefore, in this paper, we modify the pulse decay method $[40,41]$ by intermittently measuring coal permeability under two geomechanical conditions: constant confining stress and constant differential pressure, respectively. It is aimed at revealing the impact of dual-pore structure deformation on gas permeability change, due to gas transport from unsteady-state to steady-state flow. In order to minimize the sorption-induced swelling effect on solid deformation, this paper uses helium to measure coal permeability. This method can precisely evaluate the interaction of gas seepage/diffusion and porous structure deformation. Combined with the numerical simulation method, cleat-matrix interaction on the dynamic evolution of coal permeability is investigated for gas flowing from an unsteady state to a steady state. The present work also gives insight into how the evolution of coal permeability is associated with the dual-pore pressure system. 


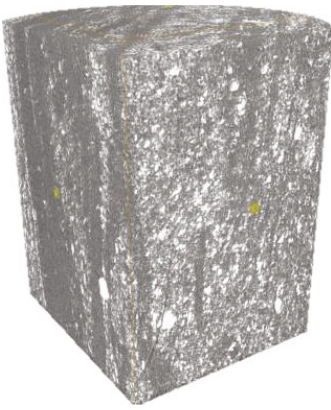

(a)

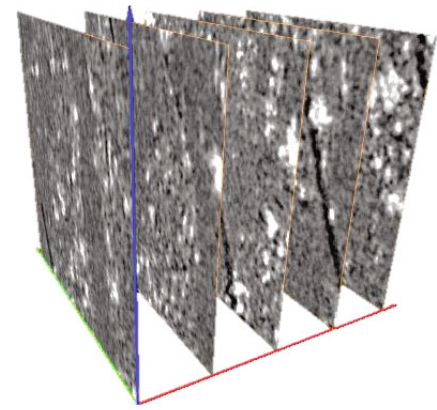

(b)

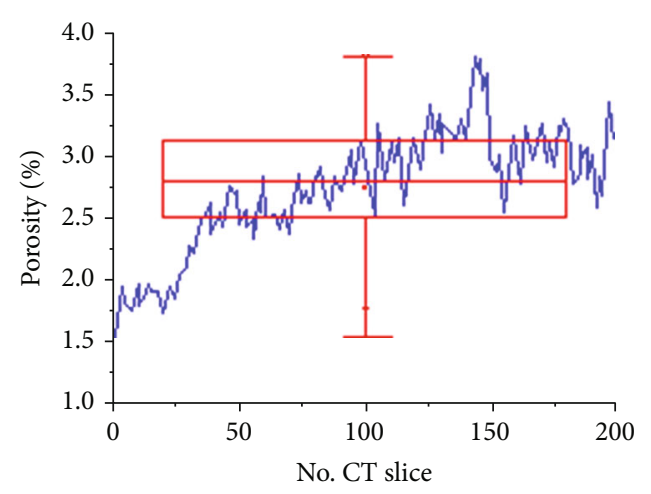

(c)

Figure 1: CT scan result: (a) a three-dimensional reconstructed coal sample; (b) distribution of cleat aperture of the coal sample; (c) mean porosity distribution.

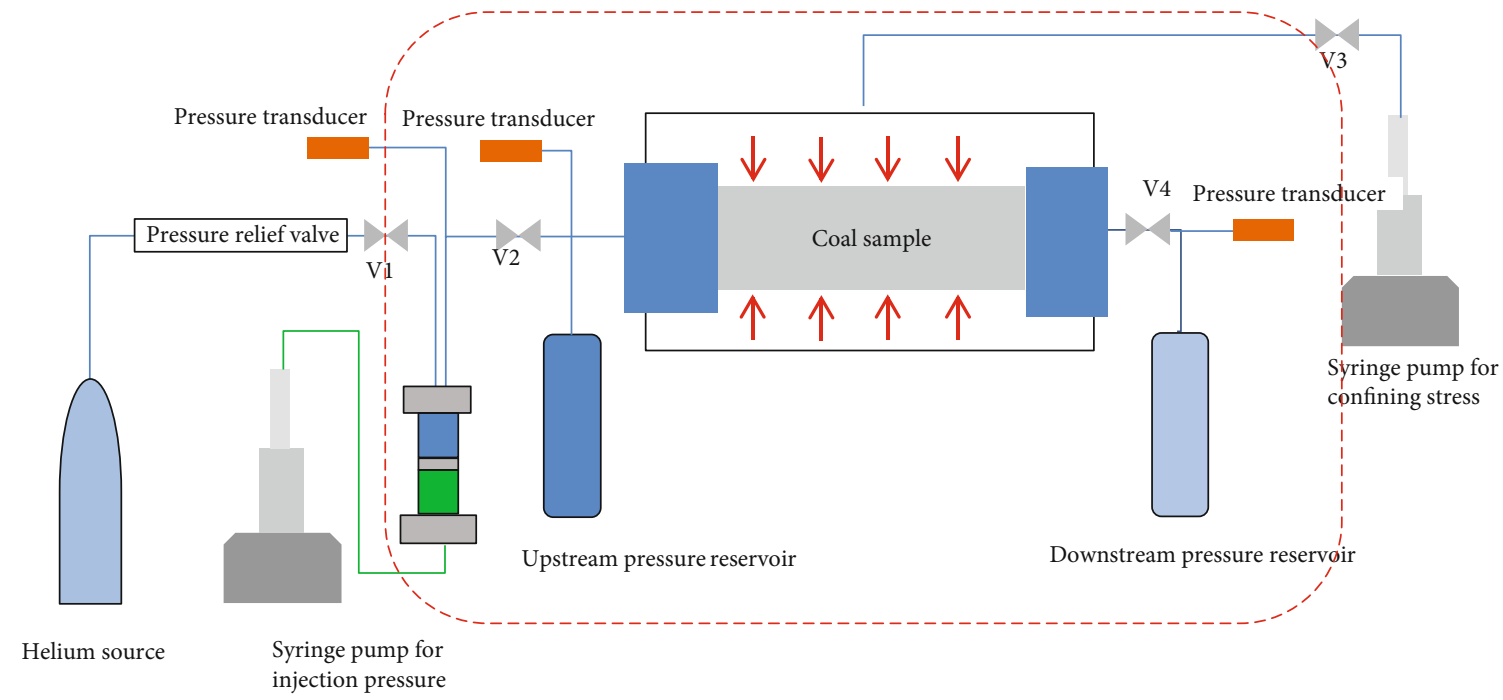

FIgURE 2: Schematic diagram of the experimental design.

\section{Experimental}

2.1. Coal Sample and Test Equipment. Coal test samples were collected from the Juye coalfield in Shandong Province in eastern China. The microscopic physical parameters are listed in previous work [39]. Permeability measurements are completed on high-volatile bituminous coal $(2.5 \mathrm{~cm}$ in diameter and $5.0 \mathrm{~cm}$ in length) cored from a block collected from the Juye coalfield in eastern China. To obtain distribution characteristics of coal cleat, the full-sized sample was scanned by using Nano-2000 X-ray machine. The X-ray machine has a resolution of $0.05 \mu \mathrm{m}$. The CT voxel data were first converted into a series of CT images and then analyzed using Avizo software. A digital coal sample was reconstructed as shown in Figure 1(a). Threshold segmentation was used to define the cleat network of the coal sample from the voxel data (Figure 1(b)). Mean porosity along the axis of the coal sample is plotted in Figure 1(c). The mean porosity of the overall coal sample is $2.6 \%$. It seems to indicate that the coal sample has few visible cleats.

The experimental setup is schematically shown in Figure 2. This facility consists of a Hassler-type core holder, two syringe pumps, a fluid-injection system, and a dataacquisition unit. A strain gauge was attached along the circumferential direction of the coal sample. The lateral surface of the coal sample was packaged by a rubber sleeve. The two ends of the sample were fully constrained by two end lugs of the core holder. The flow measurement system is composed of a gas source, a reference cell, and upstream/downstream pressure reservoirs. The two end plugs are connected to the upstream and downstream pressure reservoirs. The dataacquisition unit collects coal strain data, the upstream/downstream pressure, and the pressure/flow of the fluids injected from the syringe pump.

2.2. Experimental Procedures. The experimental conditions were divided into two conditions: (i) keeping the differential pressure between the confining stress and pore pressure at $2 \mathrm{MPa}$; (ii) increasing injection pressure under constant confining stress. The constant differential pressure condition can enable the cleat network of coal to be subjected to constant effective stress. Under this condition, the effective stresscontrolled cleat deformation is eliminated, and gas diffusion is believed to be an important reason for the evolution 
TABLE 1: Testing geomechanic conditions.

\begin{tabular}{lcc}
\hline $\begin{array}{l}\text { Geomechanic } \\
\text { condition }\end{array}$ & $\begin{array}{c}\text { Confining pressure } \\
(\mathrm{MPa})\end{array}$ & $\begin{array}{c}\text { Injection pressure } \\
(\mathrm{MPa})\end{array}$ \\
\hline Constant confining & 7 & 5 \\
pressure & 7 & 3 \\
& 7 & 1 \\
\hline \multirow{2}{*}{ Constant differential } & 5 & 3 \\
pressure & 6 & 4 \\
& 7 & 5 \\
\hline
\end{tabular}

of coal permeability. For other condition, the effective stress decreases as the gas pressure increases. This approach is used to study the dynamic permeability in the process of gas injection/depletion.

Predetermined confining stress and pore pressure are listed in Table 1. The testing procedure was divided into two steps as follows:

(1) The first step was to inject gas into the coal sample. Predetermined confining stress was applied to the sample. Once the compressive strain of the coal sample became stable, helium gas was allowed to flow into the coal sample. The coal strain was measured in real time and recorded as the downstream pressure rose to the upstream pressure

(2) The second step used the pulse decay method [22] to measure coal permeability. This method observes the decay of the differential pressure between upstream and downstream vessels connected to the coal sample. The pressure decay curve can be modeled as

$$
\frac{P_{u}-P_{d}}{P_{u 0}-P_{d 0}}=e^{-\alpha t}
$$

Here, $P_{u}-P_{d}$ is the difference between the upstream pressure and the downstream pressure, $P_{u 0}-P_{d 0}$ is the initial difference between the upstream pressure and the downstream pressure, $t$ is the time, and $\alpha$ is

$$
\alpha=\frac{k A}{\mu \beta L}\left(\frac{1}{V_{u}}+\frac{1}{V_{d}}\right),
$$

where $k$ is the permeability, $\beta$ is the compression coefficient, $L$ is the sample length, $A$ is the sample sectional area, and $V_{u}$ and $V_{d}$ are the upstream gas volume and the downstream gas volume, respectively. Coal permeability can be calculated by combining equations (1) and (2).

The pulse decay method above is required to generate a slight pressure gradient in a coal sample by increasing the upstream pressure and decreasing the downstream pressure simultaneously as shown in Figure 3(a). It is difficult to control the final equilibrium pressure between the upstream and the downstream reservoirs using this method. To obtain time-dependent cleat-matrix interaction, it is necessary to measure the coal permeability evolution with time under the same pressure condition. For this reason, a modified pulse decay method was used by only reducing the downstream pressure slightly while holding the upstream pressure [42] as plotted in Figure 3(b). In this case, the volume of the upstream reservoir $V_{u}$ is infinite. $1 / V_{u}$ is approximately equal to zero. Equation (2) can be simplified as follows:

$$
k=\frac{\alpha \mu \beta L V_{d}}{A} .
$$

After the upstream and downstream pressures reached equilibrium, the coal permeability measurement was repeated until the permeability became stable to obtain the evolutionary pattern of coal permeability.

2.3. Experimental Results. Figures 4 and 5 show the gas-solid system responses under constant confining stress and constant differential pressure conditions, respectively. Figures 4(a) and 5(a) show changes of upstream and downstream gas pressure with respect to time under different conditions. Duration of the downstream pressure equilibrating with the upstream pressure can be used to characterize gas flow through the cleat network of the coal sample. Figure 6 shows that the duration of pressure equilibrium became significantly shorter as the injection pressure increased under constant confining stress conditions. This means that the increasing pore pressure can open the cleat aperture, accordingly causing gas flow to accelerate. In contrast, under the constant differential pressure condition, the pressure equilibrium duration moderately decreased as the injection pressure increased. This phenomenon indicated that application of the constant difference pressure condition can keep the cleat aperture unchanged, in which case the gas flow is predominated by the aperture of gas flow pathway rather than pore pressure.

Bulk deformation of the coal sample is significantly related to its pore pressure change. Time-dependent evolution of the coal strain can be used to characterize gas flow through a specific porous structure. At the very beginning of the gas injection, the coal sample was found to rapidly swell. This is explained by an increase in cleat pressure controlled by Darcy's flow. The expansion deformation rate then slowed down as the downstream pressure gradually increase to the upstream pressure. This dynamic change of the solid deformation can reveal the gas flow process within the dual-porosity system: the injected gas can occupy the cleat network firstly and then migrate into the matrix system. These observations are consistent with previous publications [43-46] that the gas diffusion within the coal matrix also play a significant role in the deformation of bulk coal.

Figures 7 and 8 show the coal permeability evolutions with respect to time under the two geomechanic conditions, respectively. In either condition, the coal permeability is observed to decrease firstly and then tend to be stable at the same injection pressure condition. When the confining stress remains unchanged, higher pore pressure was applied; the measured permeability was greater. It can be explained by opening of the cleat aperture due to decreased effective stress. 


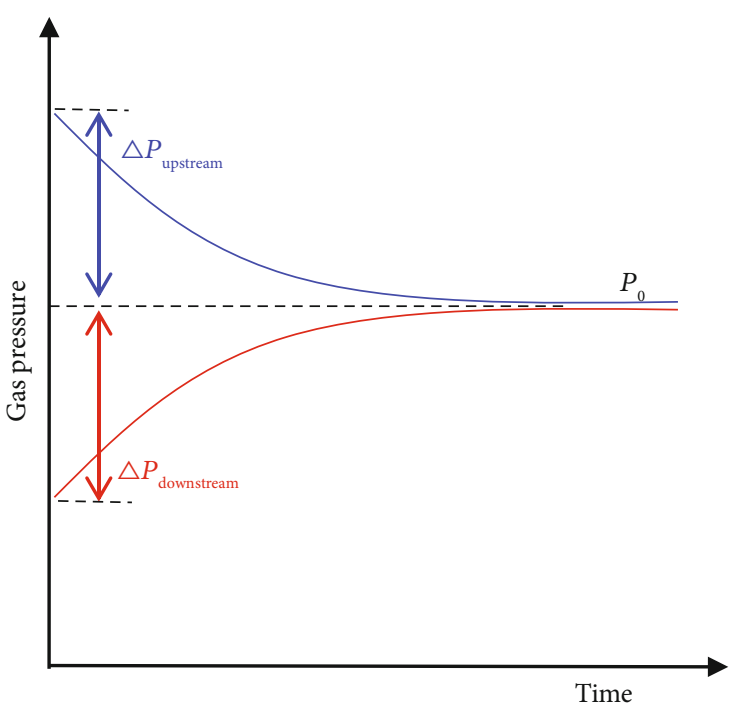

(a)

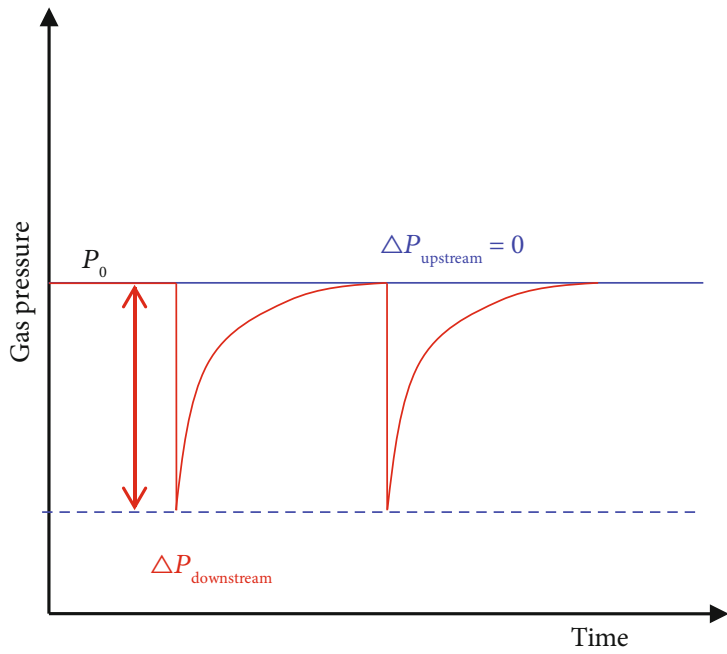

(b)

Figure 3: Gas pressure changes of the upstream reservoir and downstream reservoir. (a) Conventional pressure-pulse method; (b) modified pressure-pulse method.

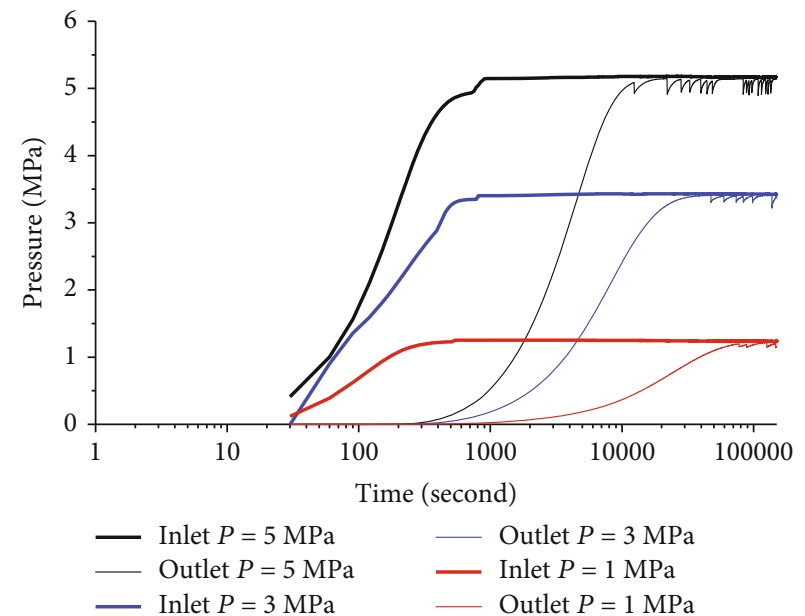

(a)

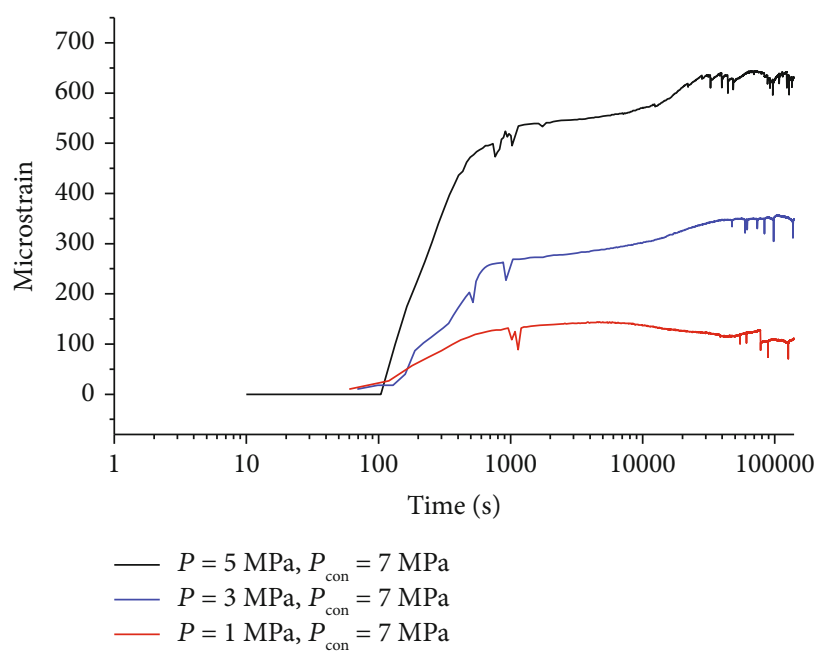

(b)

FIGURE 4: Experimental results under constant confining stress. (a) Gas pressure changes of upstream reservoir/downstream reservoir; (b) circumference strain of the coal sample.

In contrast, when the confining pressure-pore pressure difference was unchanged, higher pore pressure was applied; the measured permeability was lower. The observations are consistent with previous publications [47]. Relevant analysis and explanations are presented in Section 4.1.

It should be noted that the presented pulse decay method is required to not measure gas permeability until the cleat network pressure reached the equilibrium state. The dynamic change of the gas-solid system is only analyzed by adopting a numerical approach to gain insights into the cleat-matrix interactions triggered by fluid transient flow. In the following, a fully coupled numerical model is applied to explore the dynamic change of gas permeability, to numerically simulate the cleat-matrix interaction under various boundary conditions, and finally to compare the results with those from laboratory measurements.

\section{Numerical Analysis}

Given that a dual porosity coal contains porous matrix and fractures, we apply the overlapping continuum approach to characterize the interactions between the matrix and the fracture [48]. The following assumptions are derived: (a) bulk coal containing matrix and fractures are homogeneous, isotropic, and elastic; (b) solid strain is infinitesimal; (c) injected helium is ideal gas; (d) gas flow is followed by Darcy's law. Therefore, we define a full set of field equations that govern solid deformation and gas flow. These four continua are 


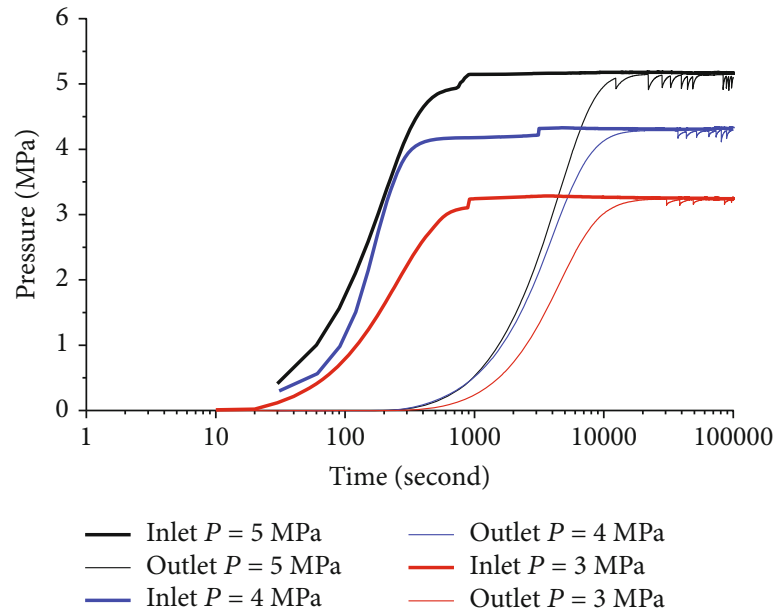

(a)

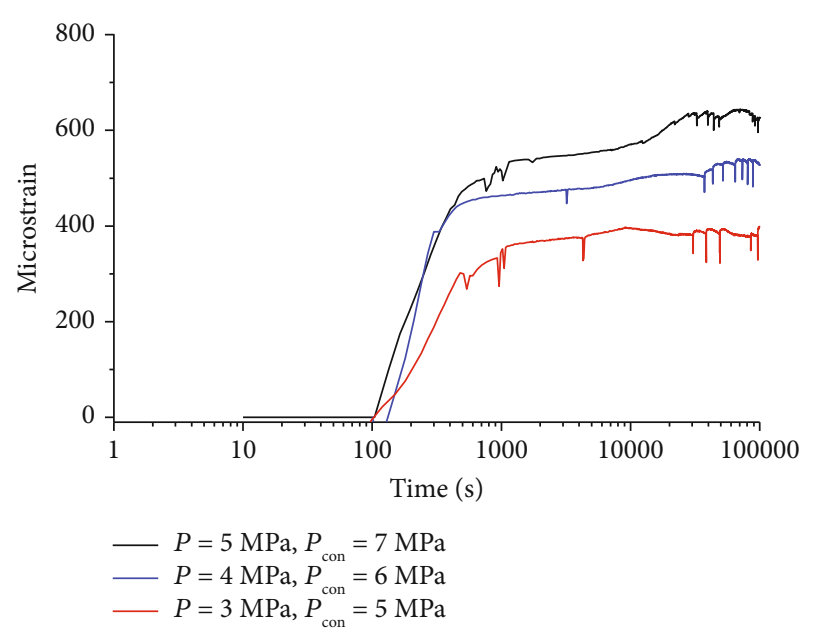

(b)

FIGURE 5: Experimental results under constant difference pressure condition. (a) Gas pressure data of upstream/downstream reservoirs; (b) circumference strain of the coal sample.

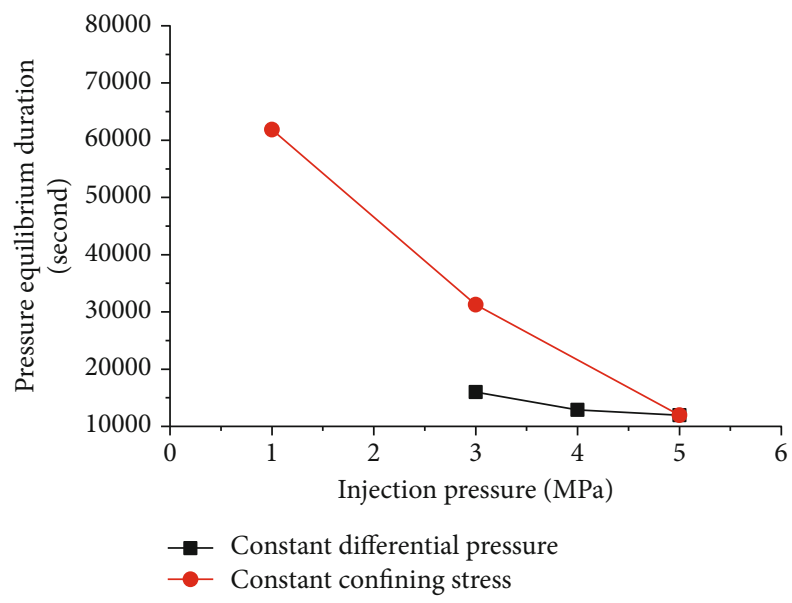

FIGURE 6: Durations of gas pressure equilibrium under different test conditions.

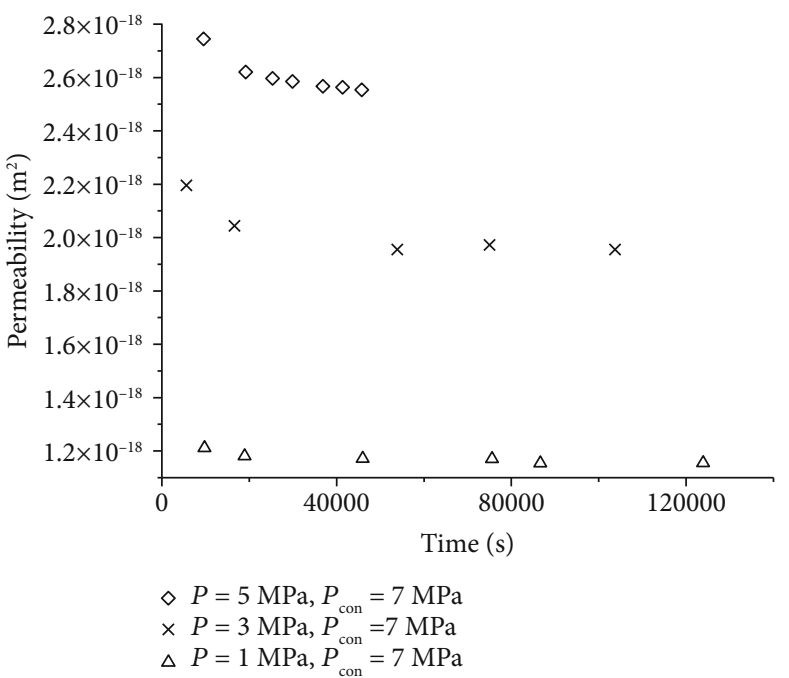

Figure 7: Permeability revolutions with time under constant confining stress condition. connected by local force balance relation, local deformation compatibility relation, and gas mass exchange relation.

\subsection{Governing Equations}

3.1.1. Governing Equations of Cleat and Matrix Deformation. Based on the poroelastic theory [49], the constitutive relation for matrix and fracture can be defined as the following, respectively $[10,48,50]$ :

$$
\begin{aligned}
\varepsilon_{f_{i j}}= & \frac{1}{2 G_{f}} \sigma_{i j}-\left(\frac{1}{6 G_{f}}-\frac{1}{9 K_{f}}\right) \sigma_{k k} \delta_{i j} \\
& +\frac{\xi_{f}}{3 K_{f}} p_{f} \delta_{i j}-\frac{1}{3 K_{f}} \Delta p \delta_{i j} \\
\varepsilon_{m_{i j}}= & \frac{1}{2 G_{m}} \sigma_{i j}-\left(\frac{1}{6 G_{m}}-\frac{1}{9 K_{m}}\right) \sigma_{k k} \delta_{i j} \\
& +\frac{\xi_{m}}{3 K_{m}} p_{m} \delta_{i j}-\frac{1}{3 K_{m}} \Delta p \delta_{i j},
\end{aligned}
$$

where $G_{m}=E_{m} /\left(2\left(1+v_{m}\right)\right)$ and $G_{f}=E_{f} /\left(2\left(1+v_{f}\right)\right)$ are the shear modulus of the matrix and cleat systems, respectively, $E_{m}$ and $E_{f}$ are Young's modulus of the matrix and cleat systems, respectively, and $v_{m}$ and $v_{f}$ are Poisson's ratios of the matrix and cleat systems, respectively. $K_{f}$ and $K_{m}$ are the bulk modulus of the cleat and the matrix, respectively. $p_{f}$ is the pore pressure in the cleat, and $p_{m}$ is the pore pressure in the matrix. $\Delta p=p_{f}-p_{m}$ is the differential pressure between the fracture and the matrix. $\delta_{i j}$ is the Kronecker. $\xi_{f}$ and $\xi_{m}$ are Biot's coefficients of the cleat and the matrix, respectively. $\sigma_{k k}$ is the total stress. 


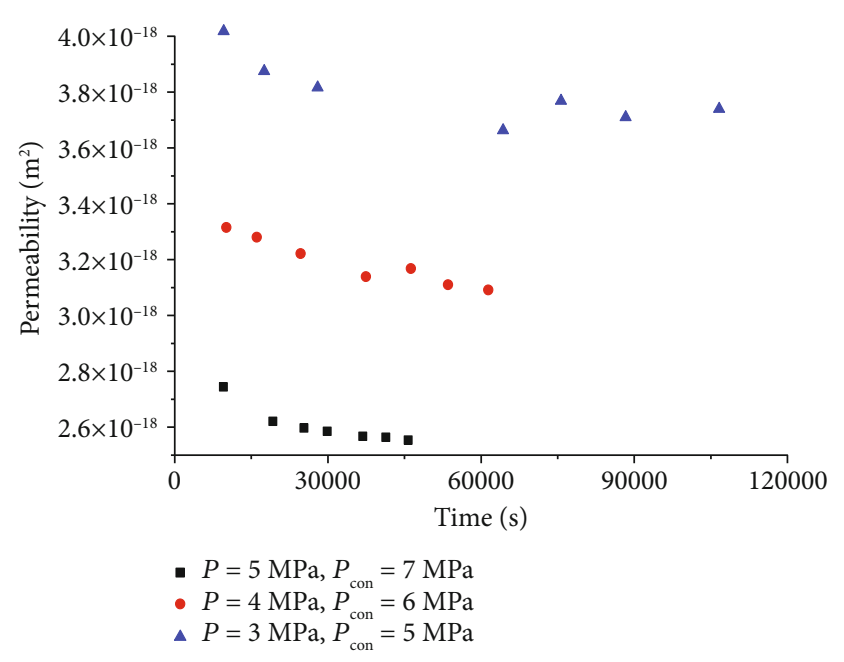

Figure 8: Permeability revolutions with time under constant difference pressure condition.

The volumetric strain of the coal block is as follows:

$$
\varepsilon_{v}=\varepsilon_{11}+\varepsilon_{22}+\varepsilon_{33}
$$

where $\varepsilon_{11}, \varepsilon_{22}, \varepsilon_{33}$ are the principle strains.

Based on this constitutive equation, the gas transfer process in the coal block can be considered the process of coupling change from the cleat and the matrix that resulted from the dynamic change between the cleat and the matrix pressures.

3.1.2. Flow Equation. Based on Darcy's Law, the flow equation of gas in coal is divided into gas flow in the cleat network for equation (6a) and gas flow in the matrix block for equation $(6 b)$ :

$$
\begin{gathered}
\frac{\partial\left(\phi_{f} \rho_{f}\right)}{\partial t}+\nabla\left(-\frac{k_{f}}{\mu} \rho_{g f} \nabla p_{f}\right)-Q=0, \\
\frac{\partial\left(\phi_{m} \rho_{m}\right)}{\partial t}+\nabla\left(-\frac{k_{m}}{\mu} \rho_{g m} \nabla p_{m}\right)+Q=0,
\end{gathered}
$$

where $\phi_{f}$ and $\phi_{m}$ are the porosities of the cleat and matrix systems, respectively, $\rho_{f}$ and $\rho_{m}$ are the gas densities of the cleat and matrix systems, respectively, $v_{f}$ and $v_{m}$ are Darcy's rates of the cleat and matrix systems, respectively, and $Q$ is the mass exchange parameter of the cleat and matrix systems.

The relation of permeability and porosity is followed by the cubic law [51]:

$$
\begin{aligned}
\frac{k_{f}}{k_{f 0}} & =\left(\frac{\phi_{f}}{\phi_{f 0}}\right)^{3}, \\
\frac{k_{m}}{k_{m 0}} & =\left(\frac{\phi_{m}}{\phi_{m 0}}\right)^{3} .
\end{aligned}
$$

The dual porosity of the coal cleat-matrix system is related to their respective effective strains $[45,52]$.

$$
\begin{gathered}
\phi_{f}=\phi_{f 0}+\xi_{f} \Delta \varepsilon_{f e}, \\
\phi_{m}=\phi_{m 0}+\xi_{m} \Delta \varepsilon_{m e},
\end{gathered}
$$

where $\Delta \varepsilon_{f e}$ is the effective strain of the cleat and $\Delta \varepsilon_{m e}$ is the effective strain of the matrix, respectively.

The effective strain of fractures is the resultant of the coal global strain and the fracture local strain. The fracture local strain is the compressive strain of the matrix block, causing fracture aperture to increase. The fracture local strain is defined as

$$
\Delta \varepsilon_{f e}=\Delta \varepsilon_{f v}+\frac{p_{f}-p_{m}}{K_{m}} .
$$

Similar with fractures, the effective strain for pores inside of matrix blocks is

$$
\Delta \varepsilon_{m e}=\Delta \varepsilon_{m v}-\frac{p_{f}-p_{m}}{K_{m}}+\frac{p_{m}}{K_{s}},
$$

where the first term represents global strain obtained from equation (4b), the second term is the compressive strain of matrix blocks resulting from the differential pressure between cleat and matrix, and the last term demonstrates the compressive strain of coal grains. They are functions of fracture and matrix pressure which could be solved from the equation of gas flow in fracture networks and equations of matrix fracture mass transport.

Substituting equation (9a) into equation (8a), the permeability equation for the cleat is given by equation (10a).

$$
\frac{k_{f}}{k_{f 0}}=\left(\phi_{f 0}+\xi_{f}\left(\Delta \varepsilon_{f v}+\frac{p_{f}-p_{m}}{K_{m}}\right)\right)^{3} .
$$

Similar with fractures, the permeability equation for the matrix is given as equation (10b), by substituting equation (9b) into equation (8b):

$$
\frac{k_{m}}{k_{m 0}}=\left(\phi_{m 0}+\xi_{m}\left(\Delta \varepsilon_{m v}-\frac{p_{f}-p_{m}}{K_{m}}+\frac{p_{m}}{K_{s}}\right)\right)^{3} .
$$

The used coal sample in laboratory measurement is a cylinder with a diameter of $25 \mathrm{~mm}$ and a height of $50 \mathrm{~mm}$. Given the mechanical/geometrical symmetry of the coal sample, the 3 -D geometry could be simplified by the 2 -D rotation model, as shown in Figure 9. The position of point of interest is the center point of the 3-D geometry. The injection pressure, $p_{\text {inlet }}$, is applied at one-end boundary, and no flow boundary is set on other-end boundary. The initial pressure for both fracture networks and matrix blocks is $p_{0}$. The confining pressure is applied on the lateral surface of the coal sample. This boundary condition allows the domain to radially deform. Input parameters for simulations are listed in Table 2. 


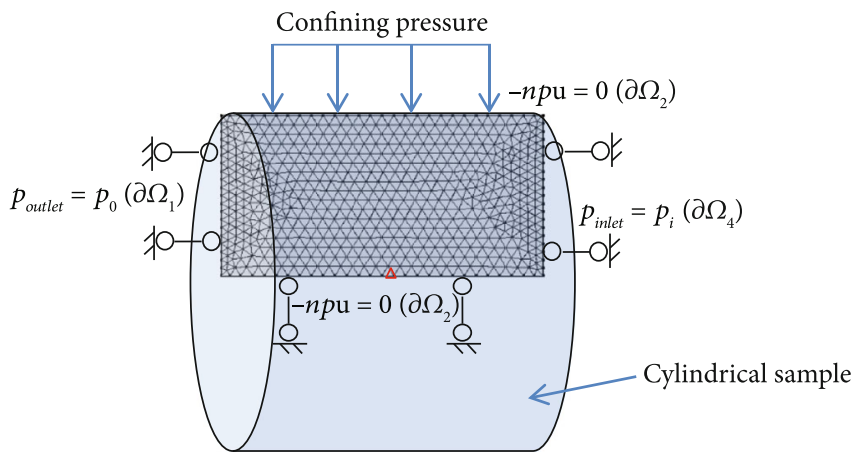

Figure 9: A model of gas injection into coal under constant confining stresses. Position of red triangle is value point of interest.

TABle 2: Physical parameters used in the numerical simulation.

\begin{tabular}{lccc}
\hline Symbol & Value & Parameter & Unit \\
\hline$E$ & $3766[41]$ & Coal Young's modulus & $\mathrm{MPa}$ \\
$E_{f}$ & $1461[41]$ & Cleat Young's modulus & $\mathrm{MPa}$ \\
$E_{m}$ & $6366[41]$ & Matrix Young's modulus & $\mathrm{MPa}$ \\
$v_{f}$ & $0.35[47]$ & Poisson's ratio of cleat & \\
$v_{m}$ & $0.35[47]$ & Poisson's ratio of matrix & \\
$\mu$ & $1.84 \times 10^{-5}$ & Gas viscosity & $\mathrm{Pa} \cdot \mathrm{s}$ \\
$\phi_{m 0}$ & 0.026 & Initial matrix porosity & \\
$\phi_{f 0}$ & 0.026 & Initial cleat porosity & \\
$k_{f 0}$ & $1.80 \times 10^{-18}$ & Initial cleat permeability & $\mathrm{m}{ }^{2}$ \\
$k_{m 0}$ & $6.00 \times 10^{-21}$ & Initial matrix permeability & $\mathrm{m}{ }^{2}$ \\
$P_{0}$ & 0.1 & Initial pore pressure & $\mathrm{MPa}$ \\
$P_{\text {in }}$ & Test value & Upstream pressure & $\mathrm{MPa}$ \\
$P_{\text {con }}$ & Test value & Confining pressure & $\mathrm{MPa}$ \\
$\rho_{c}$ & 1250 & Coal density & $\mathrm{kg} / \mathrm{m}^{3}$ \\
$P_{a}$ & 0.1 & Atmosphere pressure & $\mathrm{MPa}$ \\
$a$ & 1 & Shape factor & $\mathrm{m}{ }^{-2}$ \\
\hline
\end{tabular}

3.1.3. Coupling Equation. The correlations of gas flow/diffusion and solid deformation are fully coupled by a set of cross-coupling relations as shown in Figure 10 including (a) force balance between the matrix and the cleat, (b) matrix-fracture deformation compatibility, and (c) gas mass exchange between the matrix and the fractures. The relation of force balance between the matrix and the fractures and matrix-fracture is highly affected by the pore pressure of the fracture and the matrix. The equation of deformation compatibility is given in equation $((4 a))$ and $((4 b))$. The function of gas mass exchange between the matrix and the fractures is defined as [53]

$$
Q=\frac{a k_{m} \rho}{\mu}\left(p_{m}-p_{f}\right)
$$

where a is a shape factor and $k_{m}$ is the matrix permeability. Figure 10 shows the coupling relationship between multiple process flows and two solid deformations. Detailed interactions between different physical fields are summarized as follows:

(a) The interaction between the solid deformation and the gas flow is concurrently affected by pore pressures of the fracture and the matrix. The bulk deformation of coal varies with changes in fracture pressure $p_{f}$ and matrix pressure $p_{m}$. Accordingly, the coal deformation also affects the change in pore pressure of fracture and matrix by changing the permeability of fracture and matrix $\left(k_{m}\right.$ and $\left.k_{f}\right)$

(b) The interaction between cleat deformation and matrix deformation is controlled by the differential pressure and the geomechanic properties of fracture and matrix. Cleat aperture will be opened or narrowed by the matrix deformation caused by change of the matrix effective stress

(c) The gas flow between the fracture and the matrix is defined by the gas mass exchange terms $Q$. Due to the different permeable capacities between fracture and matrix, the gas flow rate in the fracture is faster than that of the matrix, which will lead to the existence of $\left(p_{m}-p_{f}\right)$ to promote the gas mass exchange between them

3.2. Model Verification. Figures 11 and 12 show the entire evolutions of gas permeability from gas seepage to gas diffusion under the respective geomechanical condition. The permeability evolution process is separated into two stages: During the stage I, preferential flow of the injected gas through the cleat network can increase the cleat pressure rapidly, consequently increasing the cleat aperture and its permeability. Meanwhile, the matrix blocks might suffer from bulk compression exerted by the cleat pressure. The growth of the matrix pressure is lagging behind the cleat pressure. Consequently, the differential pressure continuously increases during this stage. For the stage II, the cleat pressure reaches to the predetermined value. The injected gas begins to diffuse into the matrix, increasing the matrix pressure and the matrix permeability to a different degree. Meanwhile, the differential pressure between cleat and matrix evolves from increase to decrease. As mentioned previously, the precondition of the pulse decay method is to ensure the pore pressure to uniform over the entire coal sample before measurements. For this work, it is not until the cleat pressure reached an equilibrium state that the permeability measurement was carried out, corresponding to the third stage of modeling permeability evolution. As shown in Figures 11 and 12, the permeability in the third stage is consistent with the experimental data, which confirms the reliability of the numerical model.

\section{Discussion}

4.1. Deformation Behavior of Bulk Coal Affected by Permeability Difference between Cleat and Matrix. The coal 


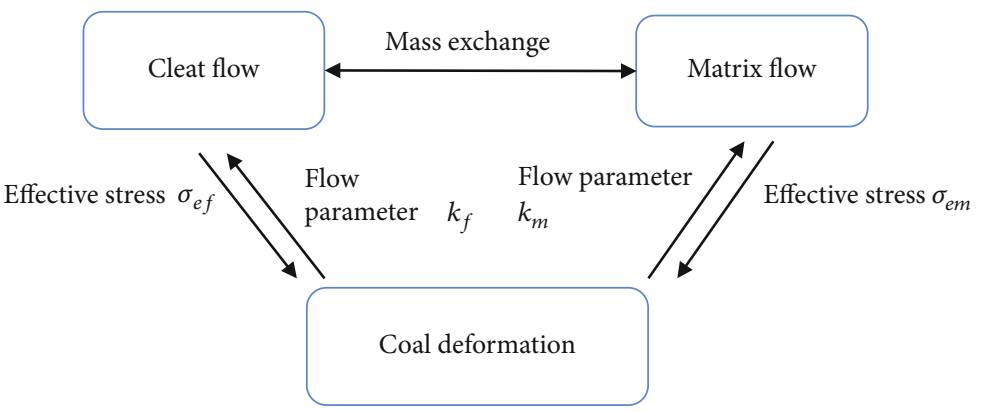

FIGURE 10: Schematic defining cross-couplings among four physical processes: matrix deformation, fracture deformation, gas flow in the matrix, and gas flow in the fracture.
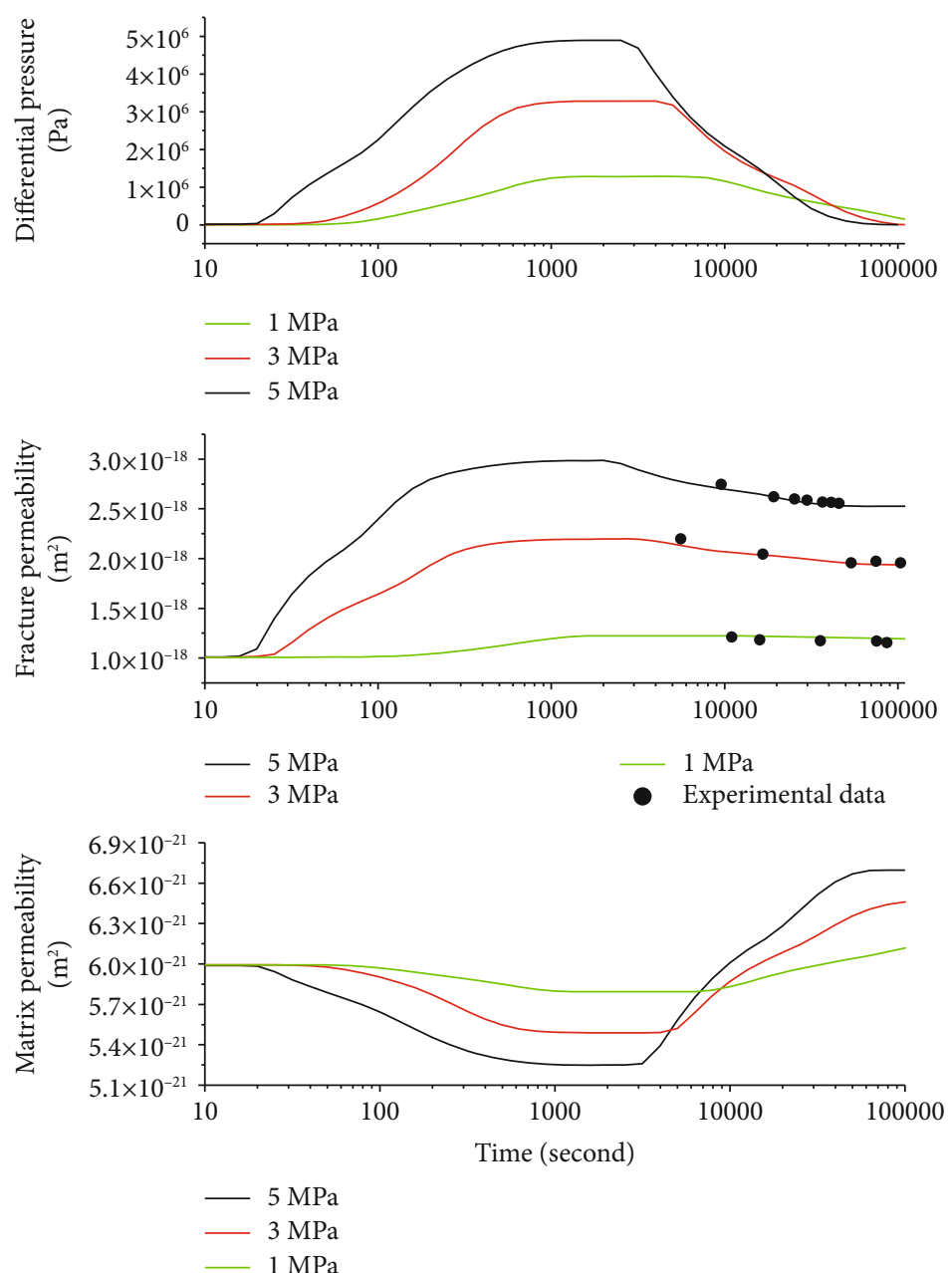

FIgURE 11: Modeling gas pressure and permeability evolutions of cleat and matrix under constant confining stress conditions.

strain evolution can provide essential information to accurately evaluate the pore pressure equilibrium process within the coal sample. Figures 4(b) and 5(b) show that the coal strain increased nonlinearly with time. This phenomenon indicates that the gas flow process was under an unsteady state. Given that the gas flow rate is positively correlated to changes in pore pressure in the cleat-matrix system, we used different ratios of initial cleat permeability to matrix permeability to reveal the cleat-matrix interaction.
Figure 13 shows that when the initial matrix permeability value is set at $0.2 \mu \mathrm{D}$, the growth of coal strain undergoes a fast-to-slow shift. During this period, the different pressure between cleat and matrix also experiences a change from increasing to decreasing. If the initial matrix permeability is decreasing, then the attenuation duration of the differential pressure is extended. Similarly, transition duration of the coal strain from rapid increase to slow increase is also prolonged. 

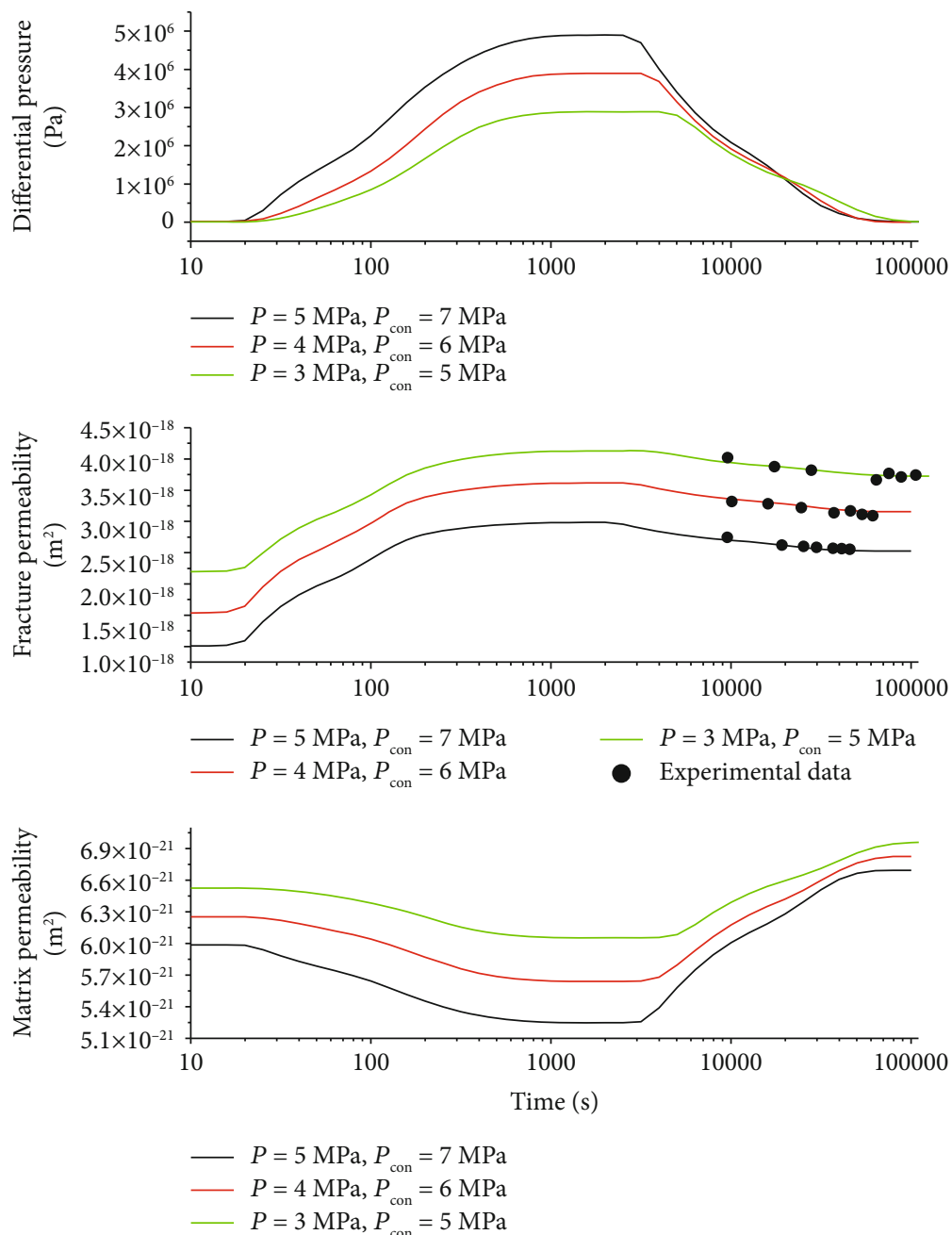

Figure 12: Modeling gas pressure and permeability evolutions of cleat and matrix under constant difference pressure conditions.

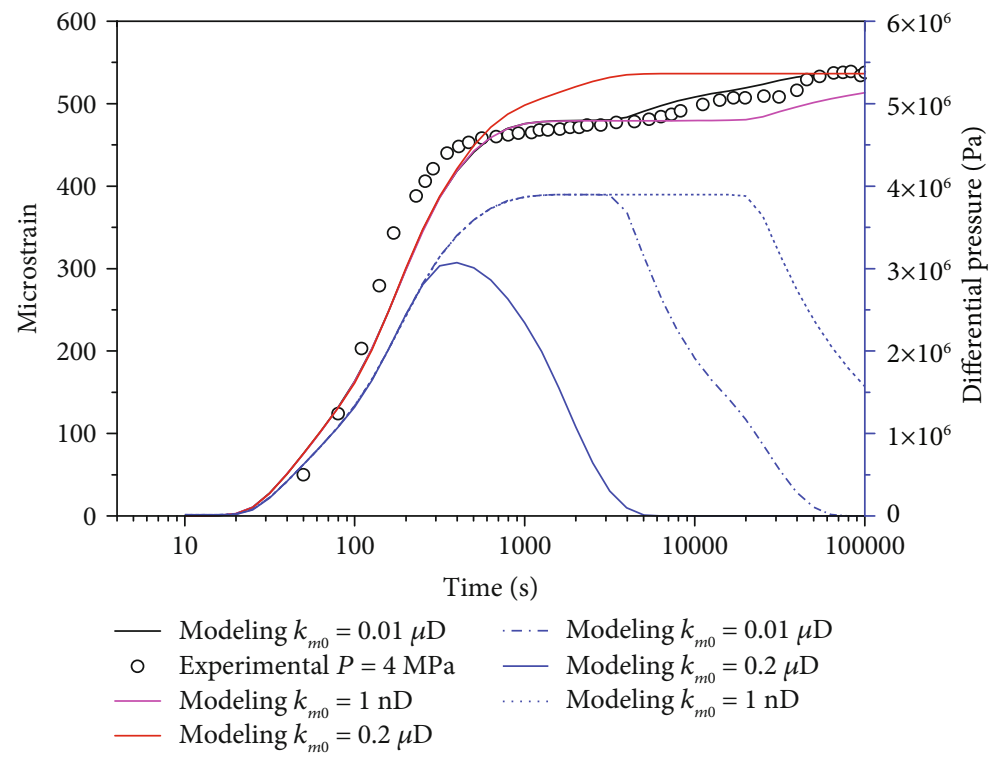

FIGURE 13: Parameter analysis of responses of bulk deformation of the coal sample to different initial matrix/cleat permeability ratios. 


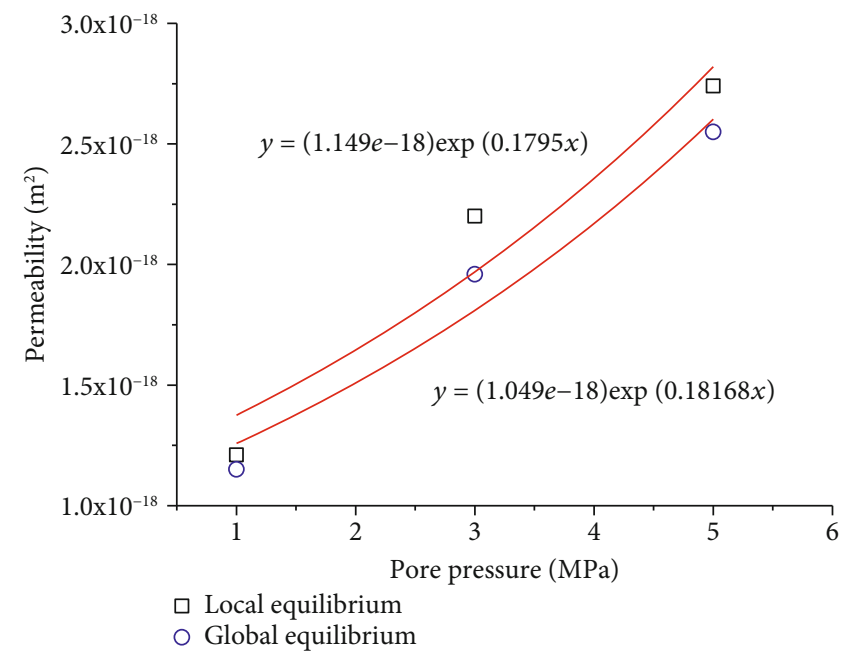

Figure 14: Pore pressure vs. local equilibrium permeability and global equilibrium permeability under constant confining stress.

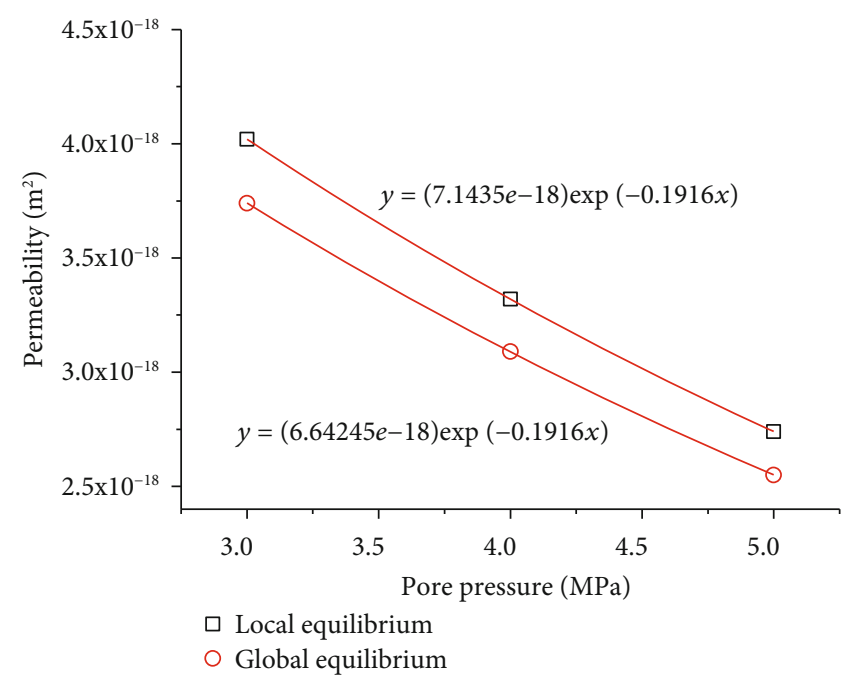

FIGURE 15: Pore pressure vs. local equilibrium permeability and global equilibrium permeability under constant difference pressure.

The pore pressure distribution of coal sample experiences a transition from local pressure equilibrium (the cleat pressure equilibrium) to global pressure equilibrium (the cleat-matrix pressure equilibrium). As a result, the coal permeability decreased under the same geomechanical condition. For the permeability-time dataset shown in Figures 11 and 12 , the first permeability data point is measured once the cleat pressure reaches the equilibrium state. This permeability value is treated as initial equilibrium permeability. The last permeability data point is not obtained until the matrix pressure reaches the equilibrium state, whose data is the global equilibrium permeability. To quantify the impact of the pore pressure equilibrium transition on the coal permeability, we plotted the local/global equilibrium permeability data with respect to pore pressure, as shown in Figures 14 and 15.
At the cases of constant confining pressure conditions, both the local equilibrium permeability and the global equilibrium permeability increased with increasing pore pressure. In contrast, both the local equilibrium permeability and the global equilibrium permeability values decreased with increasing pore pressure when the differential pressure remained unchanged. This phenomenon can be explained by increasing effective stress resulting from Biot's coefficient being less than unity [47]. In general, laboratory test conditions of constant effective stress are achieved by maintaining the difference between the confining stress and the pore pressure unchanged. This method is applicable for unipore media assuming Biot's coefficient to be unity. In fact, Biot's coefficient of coal is usually less than unity because the coal matrix also contains a number of unconnected/closed pores. Then, the pore pressure term of effective stress equation is required to multiply Biot's coefficient. Consequently, $\sigma_{e}=$ $\sigma-\xi p$ increases with increasing pore pressure. In this case, an exponential relationship between permeability and effective stress has been widely applied $[54,55]$ :

$$
k=k_{0} e^{\left(-3 c_{f}(\Delta \sigma-b \Delta p)\right)},
$$

where $k_{0}$ is the initial permeability, $c_{f}$ is the compressibility, and $b$ is the effective stress coefficient. When the exterior stress is unchanged, equation (12) becomes

$$
k=k_{0} e^{\left(-3 c_{f}(-b \Delta p)\right)} .
$$

When the different pressure $(\Delta \sigma-p)$ is unchanged, equation (12) becomes

$$
k=k_{0} e^{\left(-3 c_{f}(1-b) \Delta p\right)}
$$

Using equations (13) and (14), the initial permeability $k_{0}$, the fracture compressibility $c_{f}$, and the effective stress coefficient $b$ are obtained from the measured permeability results, respectively. Associated fitted parameters are listed in Table 3. The initial permeability of the local equilibrium state is greater than that of the global equilibrium state from the same set of measurements. This indicates that if the pore pressure of the coal sample does not reach the global equilibrium state, then the gas permeability may be overestimated by applying the pore-pressure-dependent model. In addition, both fracture compressibility and Biot's coefficient have no correlation with the pressure equilibrium state in general from the data analysis above.

4.2. Implication of Cleat-Matrix Interaction on Permeability Evolution. Extensive experimental results show that gas adsorption-induced matrix swelling has a significant impact on the dual-porosity structure of coal and its permeability [56]. Laboratory measurement permeability results are usually interpreted by a matchstick or cubic geometry model that the coal matrix blocks are assumed to be completely separated by through-going fractures. Under this assumption, the matrix swelling is unable to change fracture aperture and its permeability. This is because, for a given pore 
TABLE 3: Parameters used in permeability curve fitting.

\begin{tabular}{lcccc}
\hline Condition & Pore pressure state & Initial permeability $\left(\mathrm{m}^{2}\right)$ & Biot coefficient & ${\text { Cleat compressibility }\left(\mathrm{MPa}^{-1}\right)}^{\text {Constant confining stress }}$ \\
& Local equilibrium & $1.15 \times 10^{-18}$ & 0.48 & 0.37094 \\
& Global equilibrium & $1.06 \times 10^{-18}$ & 0.48 & 0.37085 \\
\hline \multirow{2}{*}{ Constant difference pressure } & Local equilibrium & $7.12 \times 10^{-18}$ & 0.48 & 0.37094 \\
& Global equilibrium & $6.27 \times 10^{-18}$ & 0.48 & 0.37085 \\
\hline
\end{tabular}

pressure, the ambient effective stress also exerts no influence on the effective stress of matrix. However, this explanation is not consistent with the laboratory observations, which show a dramatic reduction in permeability as the injected helium diffuses into the matrix blocks. Therefore, it is necessary to numerically model the impact of gas adsorption. Liu et al. [45] assumed two extreme cases including freeswelling boundary and constant volume boundary to evaluate the cleat-matrix interaction. Under the free-swelling case, matrix swelling deformation has no influence on the cleat aperture. The theoretical solution for the permeability is derived as

$$
\frac{k}{k_{0}}=\left(1+\frac{\alpha_{f}}{\phi_{f 0}}\left(\frac{\Delta p}{K}\right)\right)^{3} .
$$

Under the constant volume case, the absolute value of the change in the matrix deformation is equal to that of the cleat deformation. The contribution of matrix swelling to cleat aperture is $100 \%$, and the cleat permeability can be expressed by equation (13):

$$
\frac{k}{k_{0}}=\left(1+\frac{\alpha_{f}}{\phi_{f 0}}\left(\frac{\Delta p}{K_{s}}\right)\right)^{3} .
$$

Solutions of these two cases are illustrated in Figures 16 and 17, respectively. For the constant confining stress condition, both the cleat effective stress and the matrix effective stress decrease with increasing injection pressure. For the case of free swelling, the cleat permeability increases due to no influence between the cleat and the matrix. At the case of constant volume, although the swelling deformation of the matrix can fully contribute to narrowing of the cleat aperture, the residual aperture of the cleat is still proportional to the injection pressure. For the constant different pressure condition, the cleat effective stress aperture is always unchanged. In the case of free swelling, the cleat aperture is not affected by matrix swelling. As a result, the permeability remains unchanged. For the case of constant volume, swelling deformation of matrix increases with the injection pressure rising consequently narrowing the residual cleat aperture. The cleat permeability slightly decreases. Figures 16 and 17 show that the measured permeability data fall into envelope areas between the free-swelling case and the constant volume case. Under the same injection pres-

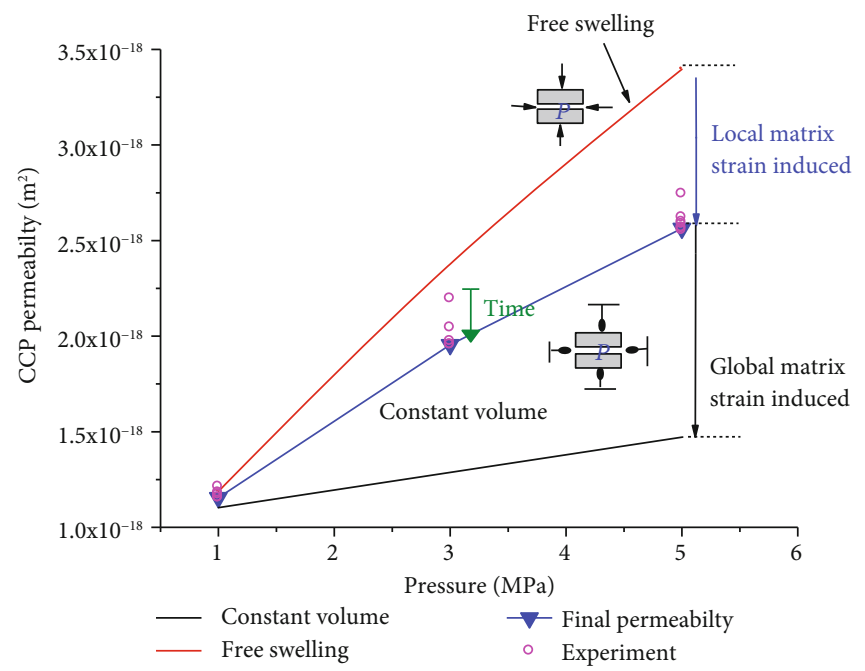

FIGURE 16: Comparison between the observed coal permeability change in the lab and the theoretical solution, both of which are bounded by free swelling and constant volumetric models (the confining pressure of the coal sample is held).

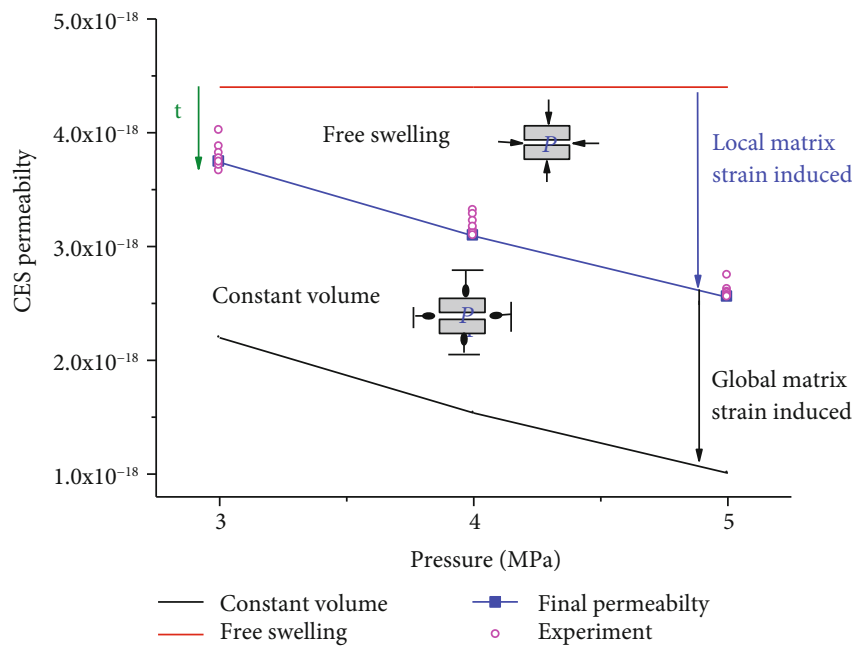

FIgURE 17: Comparison between the observed coal permeability change in the lab and the theoretical solution, both of which are bounded by free swelling and constant volumetric models (the differential pressure between the confining pressure and the injection gas pressure remains at $2 \mathrm{MPa}$ ).

sure, the decreasing permeability is observed to evolve from the free-swelling envelope to the constant volume envelope. This indicates that those theoretical assumptions based on 
the matchstick or cubic geometry are inconsistent with the presented experimental observations. These observations support Liu et al.'s viewpoints [45] that although the experiments were conducted under controlled stress conditions, the experimental measurements are more closely related to those expected under constant volume conditions.

\section{Conclusions}

(1) Since the coal cleat permeability is higher than the coal matrix permeability, the injected gas first flows through the cleat system and then diffuses into the matrix. During this process, the bulk volume of the coal sample is observed to evolve from rapid expansion to slow expansion. This phenomenon indicates that the pore pressure within the coal sample experiences a transition from a local equilibrium state (the cleat pressure equilibrium) to a global equilibrium state (the cleat-matrix pressure equilibrium). Meanwhile, the coal permeability evolution decreases with time. The results demonstrate that laboratory measurement on coal permeability is also significantly affected by the cleat-matrix pressure state. If the pore pressure of the coal sample does not reach the global equilibrium state, then the gas permeability could be overestimated by applying the pore-pressure-dependent model

(2) The coal permeability change induced by cleat-matrix interaction can be enveloped by free-swelling and constant volume boundary conditions. The results show that while permeability measurements on the coal sample are performed under stress-controlled boundary conditions, the measured permeability decreases to the envelope curve of the constant volume boundary. We show experimentally that when the cleat pressure reaches the equilibrium state, the coal permeability reduction is attributable to the swelling of matrix narrowing cleat aperture

\section{Abbreviations}

A: $\quad$ Cross-sectional area of the coal core

a: $\quad$ Shape factor

$b$ : $\quad$ Effective stress coefficient

$c_{f}$ : Compressibility

$E_{f}: \quad$ Young's modulus of the cleat system

$E_{m}$ : Young's modulus of the matrix system

$G_{f}: \quad$ The shear modulus of the cleat system

$G_{m}: \quad$ The shear modulus of the matrix system

$k: \quad$ Permeability

$k_{0}: \quad$ Initial permeability

$k_{f}$ : $\quad$ Cleat permeability

$k_{m}: \quad$ Matrix permeability

$k_{f 0}: \quad$ Initial cleat permeability

$k_{m 0}: \quad$ Initial matrix permeability

$K: \quad$ The bulk modulus of coal

$K_{f}$ : The bulk modulus of the cleat system
$K_{m}: \quad$ The bulk modulus of the matrix system

$K_{s}: \quad$ The bulk modulus of grain

L: $\quad$ Core length

$p_{f}: \quad$ The pore pressure in cleat

$p_{m}: \quad$ The pore pressure in matrix

p: $\quad$ Pore pressure

$p_{0}: \quad$ Initial pore pressure

$\Delta p: \quad$ The differential pressure between fracture and matrix

$p_{\text {in }}: \quad$ Upstream pressure

$P_{d}$ : $\quad$ Downstream pressure

$P_{u 0}: \quad$ Initial upstream pressure

$P_{d 0}: \quad$ Initial downstream pressure

$p_{\text {inlet }}: \quad$ Injection gas pressure

$P_{\text {con }}$ : Confining pressure

$P_{a}:$

Atmosphere pressure

Q: $\quad$ The mass exchange parameter of the cleat and matrix system

$t: \quad$ Time

$V_{u}: \quad$ Volume of the upstream vessels

$V_{d}$ : $\quad$ Volume of the downstream vessels

$\alpha: \quad$ Slope of the decay curve $(1 / \mathrm{s})$

$\xi: \quad$ Biot coefficient

$\xi_{f}: \quad$ Biot coefficient of cleat

$\xi_{m}: \quad$ Biot coefficient of matrix

$\beta: \quad$ Storage capacity $(1 / \mathrm{Pa})$

$\delta_{i j}: \quad$ The Kronecker delta

$\varepsilon_{11}, \varepsilon_{22}, \varepsilon_{33}$ : Main strain

$\Delta \varepsilon_{f e}: \quad$ Effective strain of the cleat

$\Delta \varepsilon_{m e}: \quad$ Effective strain of the matrix

$\Delta \varepsilon_{f v}: \quad$ Global strain of the cleat

$\Delta \varepsilon_{m v}$ : Global strain of the matrix

$\sigma / \sigma_{k k}: \quad$ Total stress

$\sigma_{e}: \quad$ Effective stress

$\phi_{f 0}$ : Initial porosities of the cleat system

$\phi_{m 0}: \quad$ Initial porosities of the matrix system

$\phi_{f}$ : $\quad$ Porosities of the cleat system

$\phi_{m}$ : $\quad$ Porosities of the matrix system

$v_{f}$ : Poisson's ratios of the matrix system

$v_{m}$ : Poisson's ratios of the cleat system

$\mu: \quad$ Viscosity of helium

$\rho_{f}: \quad$ The gas densities of the cleat system

$\rho_{m}: \quad$ The gas densities of the matrix system

$\rho_{c}: \quad$ Coal density

$v_{f}$ : Darcy's rates of the cleat system

$v_{m}$ : Darcy's rates of the matrix system.

\section{Data Availability}

The excel data used to support the findings of this study are included within the article.

\section{Conflicts of Interest}

The authors declare that they have no conflicts of interest. 


\section{Acknowledgments}

The financial support from the National Natural Science Foundation of China (No. 41772154), the China Postdoctoral Science Foundation (2018T110816), the Natural Science Foundation of Shandong Province (ZR2017MEE003, ZR2019MA009), and the SDUST Research Fund (2018TDJH102) are all gratefully acknowledged. The authors are also grateful to Nantong Feiyu Oil Science and Technology Exploration Co. Ltd. for providing testing equipment.

\section{Supplementary Materials}

Figure 4(a) file includes three groups of upstream/downstream pressure versus time, where each group is colored. Accordingly, Figure 4(b) file includes three groups of strain-time dataset, where each group is also colored. Similar to Figure 4 excel file, Figure 5 also consists of two worksheets: Figure 5(a) and Figure 5(b). Relevant experimental condition is constant different pressure condition. Figure 5(a) file includes three groups of upstream/downstream pressure versus time, where each group is colored. Accordingly, Figure 5(b) file includes three groups of strain-time dataset, where each group is also colored. Figure 7 excel file, for the constant confining stress condition, contains three groups of experimental permeability data versus time under three injection pressure conditions. Each group is colored. Figure 8 excel file, for the constant different pressure condition, contains three groups of experimental permeability data versus time under three injection pressure conditions. Each group is also colored. (Supplementary Materials)

\section{References}

[1] E. P. Robertson and R. L. Christiansen, Modeling permeability in coal using sorption-induced strain data, Idaho National Laboratory (INL), 2005.

[2] R. Pini, S. Ottiger, L. Burlini, G. Storti, and M. Mazzotti, "Role of adsorption and swelling on the dynamics of gas injection in coal," Journal of Geophysical Research, vol. 114, no. B4, 2009.

[3] R. Guo, K. Mannhardt, and A. Kantzas, "Laboratory investigation on the permeability of coal during primary and enhanced coalbed methane production," in Canadian International Petroleum Conference, pp. 1-8, Calgary, June 2007.

[4] A. S. Ranathunga, S. A. Perera, and R. P. Gamage, "An experimental study to investigate the temperature effect on permeability of Victorian brown coal during $\mathrm{CO}_{2}$ sequestration," in ISRM International Symposium-Proceedings of the 8th Asian Rock Mechanics Symposium, pp. 2851-2857, Sapporo, October 2014.

[5] S. Wang, D. Elsworth, and J. Liu, "Permeability evolution in fractured coal: the roles of fracture geometry and water-content," International Journal of Coal Geology, vol. 87, no. 1, pp. 13-25, 2011.

[6] W. Sun, H. Du, F. Zhou, and J. Shao, "Experimental study of crack propagation of rock-like specimens containing conjugate fractures," Geomechanics and Engineering, vol. 17, no. 4, pp. 323-331, 2019.
[7] N. Guanhua, S. Qian, X. Meng et al., "Effect of NaCl-SDS compound solution on the wettability and functional groups of coal," Fuel, vol. 257, article 116077, 2019.

[8] R. Liu, B. Li, and Y. Jiang, "Critical hydraulic gradient for nonlinear flow through rock fracture networks: the roles of aperture, surface roughness, and number of intersections," Advances in Water Resources, vol. 88, pp. 53-65, 2016.

[9] I. Gray, "Reservoir engineering in coal seams: part 1-the physical process of gas storage and movement in coal seams," SPE Reservoir Engineering, vol. 2, no. 1, pp. 28-34, 1987.

[10] H. Zhang, J. Liu, and D. Elsworth, "How sorption-induced matrix deformation affects gas flow in coal seams: a new FE model," International Journal of Rock Mechanics and Mining Sciences, vol. 45, no. 8, pp. 1226-1236, 2008.

[11] E. V. Vorozhtsov, A. T. Gorbachev, and A. V. Fedorov, "Calculation of the motions of gas in a coal seam with a quasilinear law of filtration," Soviet Mining Science, vol. 11, no. 4, pp. 381-388, 1975.

[12] J. E. Warren and P. J. Root, "The behavior of naturally fractured reservoirs," Society of Petroleum Engineers Journal, vol. 3, no. 3, pp. 245-255, 1963.

[13] R. W. Zimmerman and G. S. Bodvarsson, "Effective block size for imbibition or absorption in dual-porosity media," Geophysical Research Letters, vol. 22, no. 11, pp. 1461-1464, 1995.

[14] J. Q. Shi and S. Durucan, "Gas storage and flow in coalbed reservoirs: implementation of a bidisperse pore model for gas diffusion in coal matrix," in SPE Annual Technical Conference and Exhibition, Denver, CO, USA, 2003.

[15] G. R. King, T. Ertekin, and F. C. Schwerer, "Numerical simulation of the transient behavior of coal-seam degasification wells," SPE Formation Evaluation, vol. 1, no. 2, pp. 165-183, 1986.

[16] Q. Zhang, J. Choo, and R. I. Borjia, "On the preferential flow patterns induced by transverse isotropy and non-Darcy flow in double porosity media," Computer Methods in Applied Mechanics and Engineering, vol. 353, pp. 570-592, 2019.

[17] H. Kazemi, "Pressure transient analysis of naturally fractured reservoirs with uniform fracture distribution," Society of Petroleum Engineers Journal, vol. 9, no. 4, pp. 451-462, 1969.

[18] E. Ozkan, U. Ohaeri, and R. Raghavan, "Unsteady flow to a well produced at a constant pressure in a fractured reservoir," SPE Formation Evaluation, vol. 2, no. 2, pp. 186-200, 1987.

[19] D. O. Ezulike and H. Dehghanpour, "A model for simultaneous matrix depletion into natural and hydraulic fracture networks," Journal of Natural Gas Science and Engineering, vol. 16, pp. 57-69, 2014.

[20] H. A. Alahmadi, A triple-porosity model for fractured horizontal wells, Dc Language, 2010.

[21] D. Yang, Y. Zhou, X. Xia, S. Gu, Q. Xiong, and W. Chen, "Extended finite element modeling nonlinear hydromechanical process in saturated porous media containing crossing fractures," Computers and Geotechnics, vol. 111, pp. 209-221, 2019.

[22] W. F. Brace, J. B. Walsh, and W. T. Frangos, "Permeability of granite under high pressure," Journal of Geophysical Research, vol. 73, no. 6, pp. 2225-2236, 1968.

[23] Y. Yang and A. C. Aplin, "Permeability and petrophysical properties of 30 natural mudstones," Journal of Geophysical Research Solid Earth, vol. 112, no. B3, article B03206, 2007.

[24] C. Cao, T. Li, J. Shi et al., "A new approach for measuring the permeability of shale featuring adsorption and ultra-low 
permeability," Journal of Natural Gas Science and Engineering, vol. 30, pp. 548-556, 2016.

[25] H. Kumar, D. Elsworth, J. P. Mathews, and C. Marone, "Permeability evolution in sorbing media: analogies between organicrich shale and coal," Geofluids, vol. 16, no. 1, pp. 43-55, 2016.

[26] W. Song, J. Zhang, C. Wang, S. Chen, and Z. Chen, "Flow field characters near fracture entrance in supercritical carbon dioxide sand fracturing," Greenhouse Gases: Science and Technology, vol. 9, no. 5, pp. 999-1009, 2019.

[27] S. C. Jones, "A technique for faster pulse-decay permeability measurements in tight rocks," SPE Formation Evaluation, vol. 12, no. 1, pp. 19-26, 1997.

[28] T. Chen, X.-T. Feng, G. Cui, Y. Tan, and Z. Pan, "Experimental study of permeability change of organic-rich gas shales under high effective stress," Journal of Natural Gas Science and Engineering, vol. 64, pp. 1-14, 2019.

[29] L. Wang, Z. Chen, C. Wang, D. Elsworth, and W. Liu, "Reassessment of coal permeability evolution using steady-state flow methods: the role of flow regime transition," International Journal of Coal Geology, vol. 211, article 103210, 2019.

[30] K. Biao, W. Enyuan, L. Wei, and L. Zenghua, "Application of electromagnetic radiation detection in high-temperature anomalous areas experiencing coalfield fires," Energy, article 116144, 2019.

[31] C. Wang, P. Zhai, Z. Chen, J. Liu, L. Wang, and J. Xie, "Experimental study of coal matrix-cleat interaction under constant volume boundary condition," International Journal of Coal Geology, vol. 181, pp. 124-132, 2017.

[32] H. Xie, N. Guanhua, L. Shang et al., "The influence of surfactant on pore fractal characteristics of composite acidized coal," Fuel, vol. 253, pp. 741-753, 2019.

[33] H. H. Liu and J. Rutqvist, "A new coal-permeability model: internal swelling stress and fracture-matrix interaction," Transport in Porous Media, vol. 82, no. 1, article 9442, pp. 157-171, 2010.

[34] L. D. Connell, M. Lu, and Z. J. Pan, "An analytical coal permeability model for tri-axial strain and stress conditions," International Journal of Coal Geology, vol. 84, no. 2, pp. 103-114, 2010.

[35] S. Q. Lu, Y. P. Cheng, and W. Li, "Model development and analysis of the evolution of coal permeability under different boundary conditions," Journal of Natural Gas Science and Engineering, vol. 31, pp. 129-138, 2016.

[36] K. Wang, J. Zang, and G. D. Wang, “Anisotropic permeability evolution of coal with effective stress variation and gas sorption: model development and analysis," International Journal of Coal Geology, vol. 130, pp. 53-65, 2014.

[37] Y. Peng, J. Liu, Z. Pan, H. Qu, and L. Connell, "Evolution of shale apparent permeability under variable boundary conditions," Fuel, vol. 215, pp. 46-56, 2018.

[38] G. Cui, J. Liu, M. Wei, R. Shi, and D. Elsworth, "Why shale permeability changes under variable effective stresses: new insights," Fuel, vol. 213, pp. 55-71, 2018.

[39] C. Wang, J. Liu, J. Feng, M. Wei, C. Wang, and Y. Jiang, "Effects of gas diffusion from fractures to coal matrix on the evolution of coal strains: experimental observations," International Journal of Coal Geology, vol. 162, pp. 74-84, 2016.

[40] E. van Oart, "A novel technique for the investigation of drilling fluid induced borehole instability in shales," in Rock Mechanics in Petroleum Engineering, Delft, The Netherlands, August 1994.

[41] D. S. Yang, W. Wang, W. Z. Chen, X. J. Tan, and L. G. Wang, "Revisiting the methods for gas permeability measurement in tight porous medium," Journal of Rock Mechanics and Geotechnical Engineering, vol. 11, no. 2, pp. 263-276, 2019.

[42] D. S. Yang, W. Wang, W. Z. Chen, J. P. Yang, and S. G. Wang, "Experimental Investigation on the stress sensitivity of permeability in naturally fractured shale," Environmental Earth Sciences, vol. 78, no. 2, p. 55, 2019.

[43] Y. Wu, J. Liu, D. Elsworth, Z. Chen, L. Connell, and Z. Pan, "Dual poroelastic response of a coal seam to $\mathrm{CO}_{2}$ injection," International Journal of Greenhouse Gas Control, vol. 4, no. 4, pp. 668-678, 2010.

[44] A. Mitra, S. Harpalani, and S. Liu, "Laboratory measurement and modeling of coal permeability with continued methane production: Part 1 - Laboratory results," Fuel, vol. 94, pp. 110-116, 2012.

[45] J. S. Liu, Z. W. Chen, D. Elsworth, H. Qu, and D. Chen, "Interactions of multiple processes during CBM extraction: A critical review," International Journal of Coal Geology, vol. 87, no. 3-4, pp. 175-189, 2011.

[46] J. Liu, J. Wang, Z. Chen, S. Wang, D. Elworth, and Y. Jiang, "Impact of transition from local swelling to macro swelling on the evolution of coal permeability," International Journal of Coal Geology, vol. 88, no. 1, pp. 31-40, 2011.

[47] Z. Chen, Z. Pan, J. Liu, L. D. Connell, and D. Elsworth, "Effect of the effective stress coefficient and sorption-induced strain on the evolution of coal permeability: Experimental observations," International Journal of Greenhouse Gas Control, vol. 5, no. 5, pp. 1284-1293, 2011.

[48] S. Zhang, J. Liu, M. Wei, and D. Elsworth, "Coal permeability maps under the influence of multiple coupled processes," International Journal of Coal Geology, vol. 187, pp. 71-82, 2018.

[49] E. Detournay and A. H. D. Cheng, "Fundamentals of poroelasticity," in Comprehensive Rock Engineering, C. Fairhurst, Ed., vol. 2, pp. 113-171, Pergamon, Oxford, 1993.

[50] H. L. Ramandi, P. Mostaghimi, R. T. Armstrong, M. Saadatfar, and W. V. Pinczewski, "Porosity and permeability characterization of coal: a micro-computed tomography study," International Journal of Coal Geology, vol. 154-155, pp. 57-68, 2016.

[51] S. Harpalani and A. Schraufnagel, "Measurement of parameters impacting methane recovery from coal seams," International Journal of Mining and Geological Engineering, vol. 8, no. 4, pp. 369-384, 1990.

[52] Y. Peng, J. Liu, M. Wei, Z. Pan, and L. D. Connell, "Why coal permeability changes under free swellings: new insights," International Journal of Coal Geology, vol. 133, pp. 35-46, 2014.

[53] E. Ranjbar and H. Hassanzadeh, "Matrix-fracture transfer shape factor for modeling flow of a compressible fluid in dual-porosity media," Advances in Water Resources, vol. 34, no. 5, pp. 627-639, 2011.

[54] J. P. Seidle, D. J. Jeansonne, and D. J. Erickson, “Application of matchstick geometry to stress dependent permeability in coals," in SPE Rocky Mountain Regional Meeting, Casper, Wyoming, May 1992.

[55] J.-Q. Shi and S. Durucan, "Exponential growth in San Juan Basin Fruitland coalbed permeability with reservoir drawdown: model match and new insights," SPE Reservoir Evaluation \& Engineering, vol. 13, no. 6, pp. 914-925, 2010.

[56] Y. Tan, Z. Pan, X. Feng, and D. Zhang, "Laboratory characterisation of fracture compressibility for coal and shale gas reservoir rocks: a review," International Journal of Coal Geology, vol. 204, pp. 1-17, 2019. 

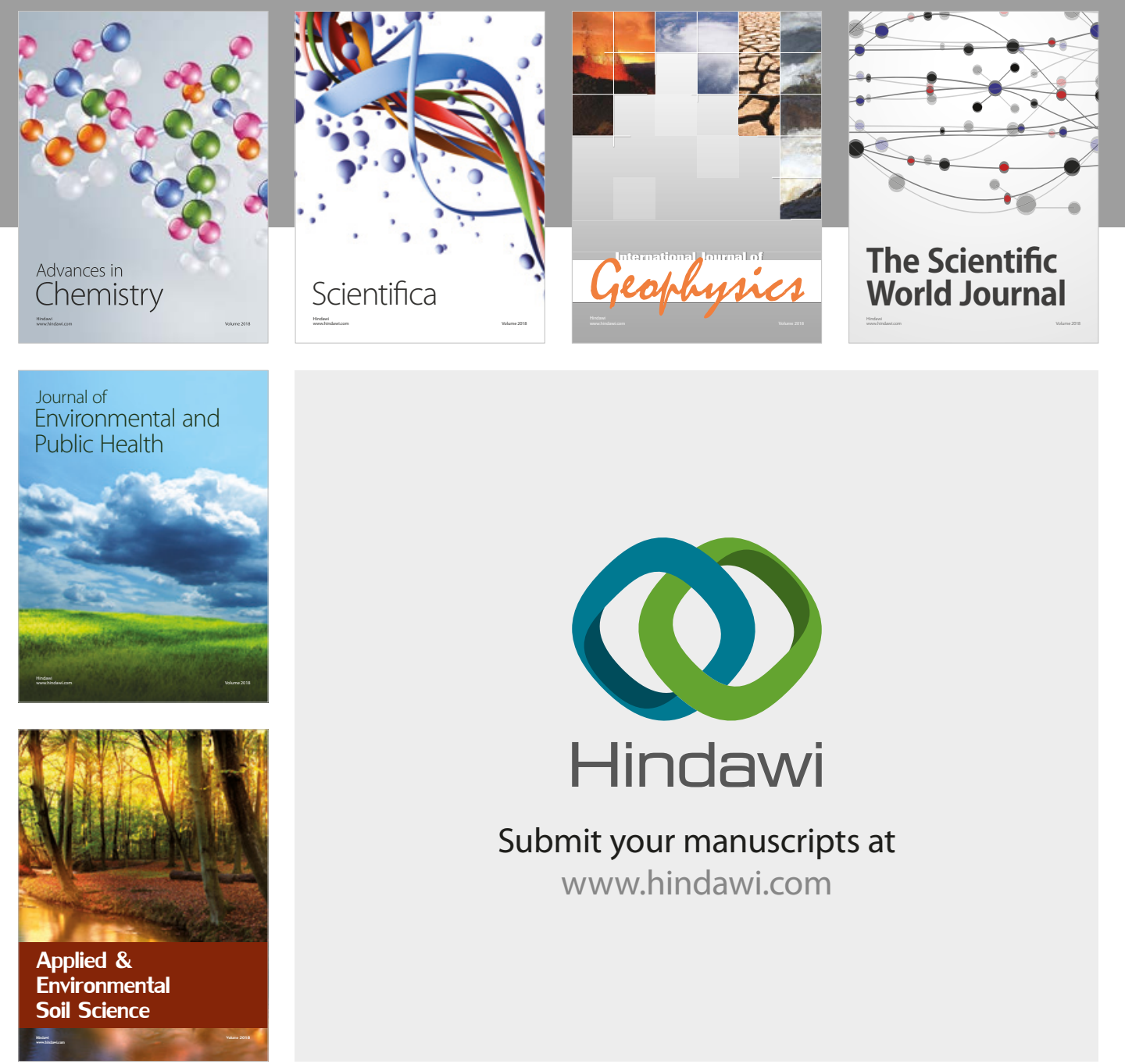

The Scientific

\section{World Journal}
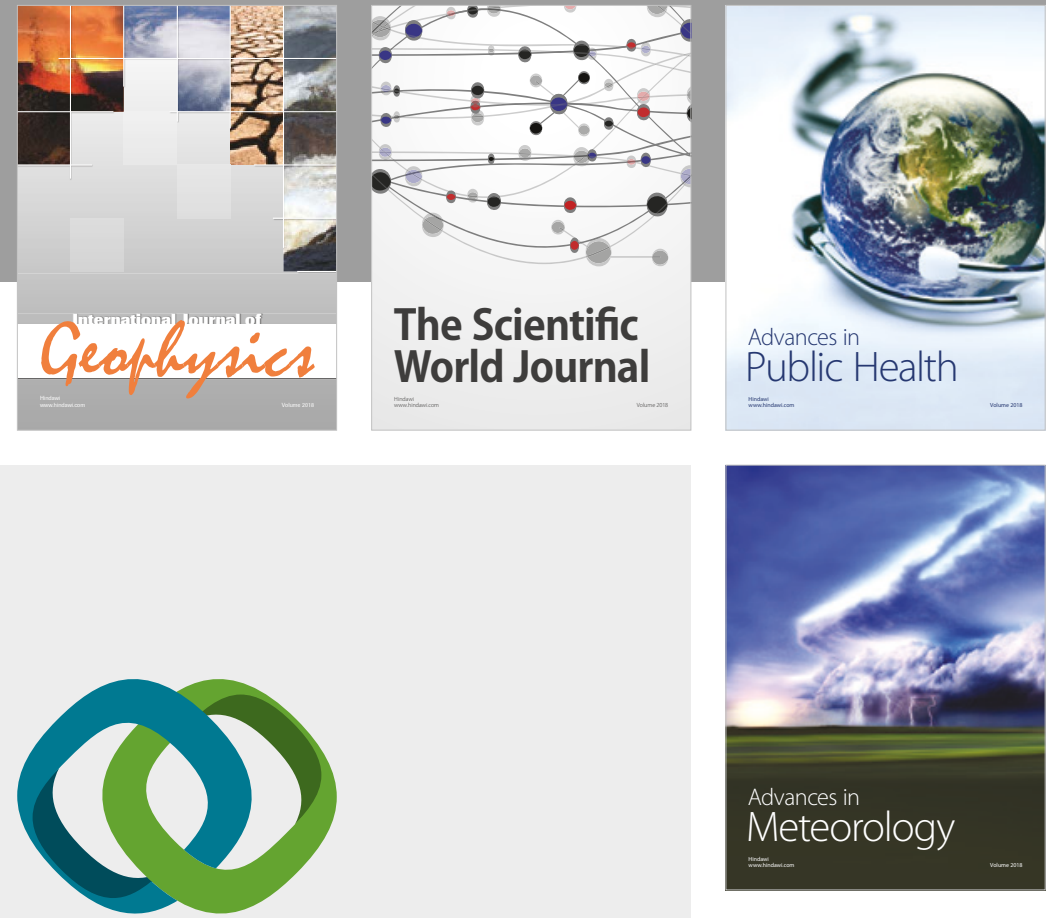

Advan

Public Health

\section{Hindawi}

Submit your manuscripts at

www.hindawi.com
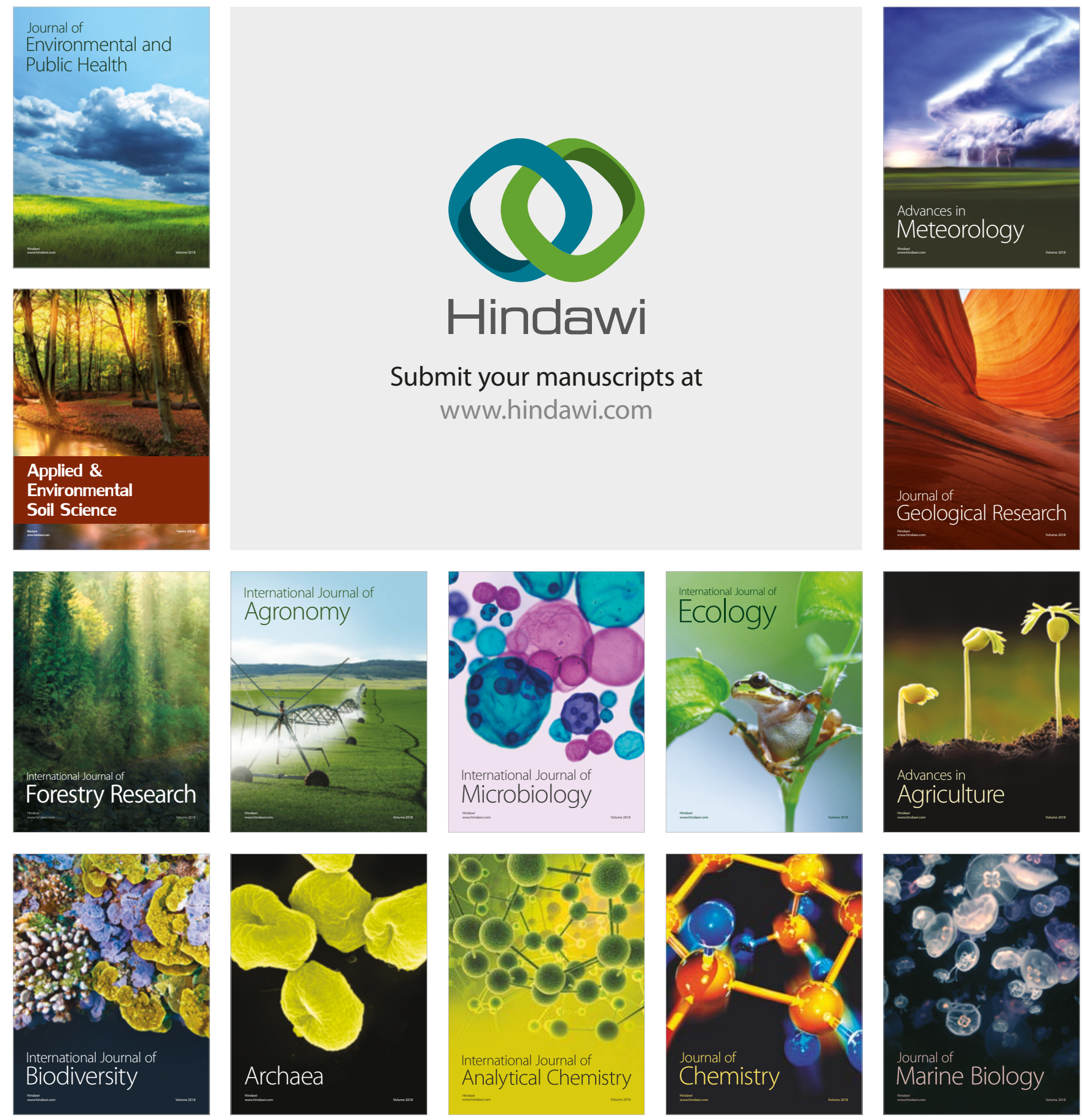